\title{
A Survey of Changes in Cloud Cover and Cloud Types over Land from Surface Observations, 1971-96
}

\author{
STEPHEN G. WARREN AND Ryan M. EASTMAN \\ Department of Atmospheric Sciences, University of Washington, Seattle, Washington \\ Carole J. Hahn \\ Department of Atmospheric Sciences, The University of Arizona, Tucson, Arizona
}

(Manuscript received 20 January 2006, in final form 20 June 2006)

\begin{abstract}
From a dataset of weather observations from land stations worldwide, about 5400 stations were selected as having long periods of record with cloud-type information; they cover all continents and many islands. About 185 million synoptic reports were analyzed for total cloud cover and the amounts of nine different cloud types, for the 26-yr period 1971-96. Monthly and seasonal averages were formed for day and night separately.

Time series of total-cloud-cover anomalies for individual continents show a large decrease for South America, small decreases for Eurasia and Africa, and no trend for North America. The largest interannual variations $(2.7 \%)$ are found for Australia, which is strongly influenced by ENSO. The zonal average trends of total cloud cover are positive in the Arctic winter and spring, $60^{\circ}-80^{\circ} \mathrm{N}$, but negative in all seasons at most other latitudes. The global average trend of total cloud cover over land is small, $-0.7 \%$ decade $^{-1}$, offsetting the small positive trend that had been found for the ocean, and resulting in no significant trend for the land-ocean average.

Significant regional trends are found for many cloud types. The night trends agree with day trends for total cloud cover and for all cloud types except cumulus. Cirrus trends are generally negative over all continents. A previously reported decline in total cloud cover over China and its neighbors appears to be largely attributable to high and middle clouds. Global trends of the cloud types exhibit trade-offs, with convective cloud types increasing at the expense of stratiform clouds, in both the low and middle levels.

Interannual variations over Europe, particularly of nimbostratus, are well correlated with the North Atlantic Oscillation; significant correlations are also found across northern Asia. Interannual variations in many parts of the Tropics are well correlated with an ENSO index. Little correlation was found with an index of smoke aerosol, in seven regions of seasonal biomass burning.

In the middle latitudes of both hemispheres, seasonal anomalies of cloud cover are positively correlated with surface temperature in winter and negatively correlated in summer, as expected if the direction of causality is from clouds to temperature.
\end{abstract}

\section{Introduction}

Clouds are important in the earth's climate system because of their effects on solar radiation, terrestrial radiation, and precipitation. These effects depend on cloud height, thickness, horizontal extent, horizontal variability, water content, phase (liquid or ice), and the sizes of droplets and crystals. It is therefore useful to

Corresponding author address: Stephen G. Warren, Department of Atmospheric Sciences, University of Washington, Box 351640, Seattle, WA 98195.

E-mail: sgw@atmos.washington.edu distinguish different types of clouds. The visual appearance of clouds is often taken to indicate characteristic atmospheric dynamical processes, so the traditional classification by weather observers of cloud types based on their appearance (WMO 1956) continues to be a useful classification in studies of cloud processes (Houze 1993).

The climatic effects of clouds further depend on the geographical location of the clouds, the albedo and temperature of the underlying surface, and the season of the year and time of day. The effect of clouds on the earth's radiation budget, the "cloud radiative forcing" (Ramanathan et al. 1989; Harrison et al. 1990), is gen-

DOI: 10.1175/JCLI4031.1

(C) 2007 American Meteorological Society 
erally negative in the daytime but positive at night, so an accurate determination of the diurnal cycle of each cloud type is important.

Because of the large effects of clouds on climate, and the diversity of model predictions of cloud feedbacks (Cess et al. 1990), it is appropriate to inquire whether the long record of visual observations of clouds can be used to infer interannual variations and trends.

We are in the process of preparing a second edition of our climatic atlases of cloud cover and cloud types (Warren et al. 1986, 1988), extending the period of record by $15 \mathrm{yr}$ and applying a moonlight criterion to the nighttime observations (Hahn et al. 1995) so as to obtain more reliable diurnal cycles. As part of that project we undertook the analysis of interannual variations and trends reported here, both for their own interest and also to help improve the cloud climatology by identifying stations with questionable observations. In this paper our purpose is to introduce the reader to the cloud databases and to demonstrate how they can be used for analysis of interannual variations and trends. We attempt explanations for some of the patterns we present.

There has been much prior work analyzing data from particular countries or regions for variations of cloud cover, and some work on cloud-type variations. Those studies focused mostly on long-term trends, for Europe (Henderson-Sellers 1986), North America (HendersonSellers 1989; Milewska 2004), Australia (Jones and Henderson-Sellers 1992), the United States (Sun 2003; Sun and Groisman 2004; Groisman et al. 2004; Dai et al. 2006), and the Former Soviet Union (Sun and Groisman 2000; Sun et al. 2001). In most regions total cloud cover appeared to increase since 1950 or earlier. We also examine trends in this paper, both for total cloud cover and for cloud types, but just as one aspect of the more general topic of cloud variations. We find that for the restricted period 1971-96 the cloud cover was decreasing on many continents, and that some of these trends are linked to ENSO variations.

\section{Database of cloud reports}

The first step in producing a cloud climatology was to obtain a database of cloud reports. We use only the reports made in the "synoptic" code of the World Meteorological Organization (WMO 1974) because it is used worldwide on both land and sea. In some countries other codes are used that are specific to those countries (appendix of Sun et al. 2001), but a parallel cloud report is also made in the synoptic code.

The synoptic weather reports from land stations that we use were originally taken from an archive of the Fleet Numerical Oceanography Center (FNOC) for the years 1971-76 and from an archive of the National Cen- ters for Environmental Prediction [NCEP, formerly the National Meteorological Center (NMC)] for the years 1977-96. Because of changes in procedures at NCEP, the NCEP data do not contain cloud-type information after March 1997. Thus, this climatology terminates with 1996 data; a different data source will be used in the future to continue our analysis beyond 1996. Surface synoptic weather reports for both land and ocean (from different source datasets) were processed, edited, and rewritten to provide a consolidated dataset of individual observations of clouds. Those observations have passed through all our processing procedures and quality controls, so they are ready to be used in computing averages. The dataset is called the Extended Edited Cloud Reports Archive (EECRA). It is available from the Department of Energy's Carbon Dioxide Information Analysis Center (CDIAC; http://cdiac.ornl. gov/epubs/ndp/ndp026c/ndp026c.html), along with our documentation (Hahn and Warren 1999). The documentation discusses the procedures we used in preparing these data and the problems with source data that we dealt with. We are now analyzing the EECRA to produce a global cloud climatology. The land analysis has been completed; the ocean analysis is nearly complete.

In addition to cloud information, the EECRA also gives, for each report, the solar zenith angle and the relative lunar illuminance. Nighttime observations are more reliable when the clouds are illuminated by bright moonlight. The lunar illuminance is computed from the lunar phase and elevation, and the earth-moon distance. A criterion for adequacy of moonlight for visual cloud detection was determined by Hahn et al. (1995); this criterion is approximately equal to the illumination from a half-moon at zenith. The EECRA also includes a flag to indicate whether this criterion was satisfied by either moonlight, twilight, or sunlight. About $38 \%$ of the observations made with the sun below the horizon satisfy the criterion.

\section{Selection of stations}

Hahn and Warren (1999) listed 11586 stations for which cloud-type information was reported at least once in the EECRA. To produce a cloud climatology for land stations, we selected stations that have sufficiently long periods of record for analysis of trends, and sufficient numbers of observations at night for analysis of diurnal cycles.

We initially selected stations if they met three criteria: 1) they normally report cloud types, 2) they had at least 20 observations in each of at least $15 \mathrm{yr}$ (during the 26-yr period) for either January or July, and 3) the number of "night" observations (i.e., made between 
TABLE 1. Number of weather stations selected for analysis of cloud variations (by region).

\begin{tabular}{lc}
\hline \multicolumn{1}{c}{ Region } & No. of stations \\
\hline Former Soviet Union (FSU) & 1558 \\
Europe (excluding FSU) & 1190 \\
China & 586 \\
Asia (excluding FSU and China) & 507 \\
Africa & 452 \\
North and Central America & 498 \\
South America & 268 \\
Pacific Islands & 226 \\
Australia & 74 \\
Antarctica & 29 \\
Total & 5388 \\
\hline
\end{tabular}

1800 and 0600 local time) was at least $15 \%$ of the total number of observations. (On average, night observations contribute about $30 \%$ of the total because we reject many observations when screening by the illuminance criterion.)

The number of stations meeting all three criteria was 5158. However, this group of stations left some significant land areas south of $30^{\circ} \mathrm{N}$ unrepresented (in Africa, South America, Australia, and Antarctica). We therefore added some stations south of $30^{\circ} \mathrm{N}$ that had fewer than $15 \mathrm{yr}$ represented, or that made reports only during daytime. (A station was added only if it occupied a $5^{\circ}$ grid box that was not already represented by the original group of 5158 stations.) The number of stations added was 230, giving a total of 5388 stations selected (Table 1). The number of these stations that had 20 or more usable daytime cloud-type observations per month, for each year, is plotted in Fig. 1. (This figure is for July, but all other months are similar.) The number of such stations was rising in the 1970s but has been declining since 1990. The total number of observations used in this climatology is 185 million.

It is notable that few stations in the United States offer the full $26 \mathrm{yr}$ of synoptic cloud reports. With the installation of the Automatic Surface Observing System (ASOS) in the mid-1990s (Warren et al. 1991), most stations in the United States stopped reporting cloud observations in the synoptic-code format around 1995 (appendix H of Hahn and Warren 1999). This was one reason for setting 1996 as an interim stopping point in construction of our database, but the database can be updated in the future for the remaining $98 \%$ of the world.

The resulting cloud climatology for each of the selected stations is available from CDIAC (http://cdiac. ornl.gov/epubs/ndp/ndp026d/ndp026d.html; Hahn and Warren 2003). We also have mapped the land cloud analyses at $5^{\circ}$ latitude-longitude resolution. Approxi-

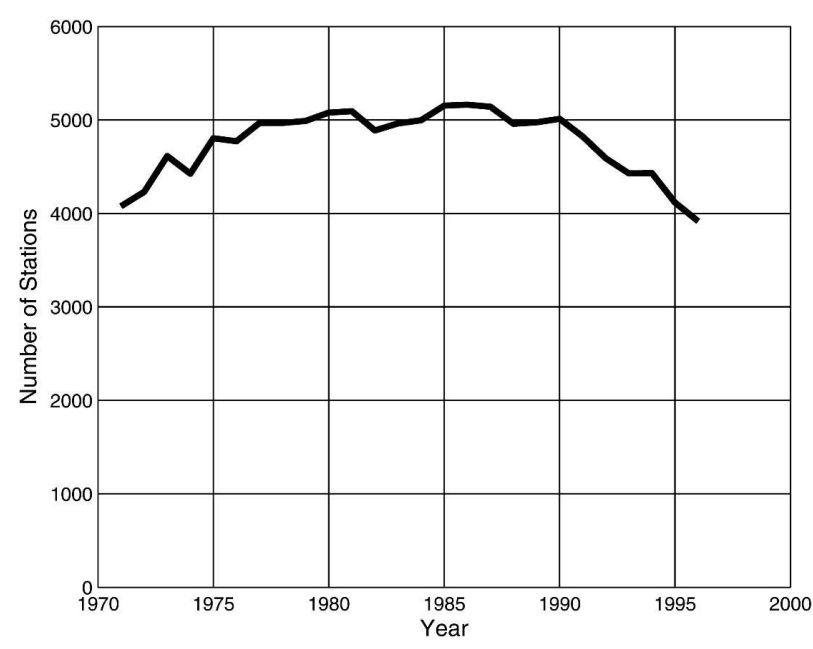

FIG. 1. Number of stations contributing at least 20 daytime observations per month (for the month of July in each year).

mately 1000 maps are available on our Web site (http:// www.atmos.washington.edu/CloudMap/), from which digital values can also be downloaded. The land station climatology is what we analyze in the work reported here.

\section{Classification of cloud types and computation of average cloud amounts}

The synoptic code defines a total of 27 cloud types, 9 for each of 3 levels (WMO 1956, 1974). For our analysis we have grouped the clouds into nine groups: five low, three middle, and one high, recognizing that the observer at the ground can most accurately report the low clouds. The amounts of middle and high clouds are less reliably determined than those of the low clouds because they are often partially or totally obscured by lower clouds; we obtain their frequencies of occurrence from a subset of observations in which their level was observable (Hahn and Warren 2003). We did attempt a subdivision of the high clouds but found that national boundaries appeared in our climatology, indicating subtle differences in observing practices in different countries with regard to classification of the nine types of cirriform clouds. We therefore have grouped all the high clouds together. Table 2 lists the nine cloud groups we distinguish, together with our computation of their global average amounts, and base heights for the low clouds.

The method of computing average cloud amounts, as described by Warren and Hahn (2002), is as follows. The "amount" of a cloud type is defined as the fraction of the sky covered by that type, whether visible or hidden behind another cloud. The time-averaged amount 
TABLE 2. Global average cloud-type amounts and heights from surface observations. [The methods for computation of average amounts and heights are given by Warren et al. (1986) and Hahn and Warren (2003).] The cloud "amount" is the average percent of the sky covered. The amounts of all the cloud types add up to more than the total cloud cover because of overlap. Land values are for 1971-96. Ocean values are preliminary for 1954-97. This table is modified from Table 3 of Warren and Hahn (2002).

\begin{tabular}{lrrrrr}
\hline \hline & \multicolumn{2}{c}{$\begin{array}{c}\text { Annual } \\
\text { average } \\
\text { amount (\%) }\end{array}$} & & \multicolumn{2}{c}{$\begin{array}{c}\text { Base height } \\
\text { (meters } \\
\text { above surface) }\end{array}$} \\
\cline { 2 - 3 } \cline { 5 - 6 } \multicolumn{1}{c}{ Cloud type } & Land & Ocean & & Land & Ocean \\
\hline Fog & 1 & 1 & & 0 \\
Stratus (St) & 5 & 12 & & 500 & 400 \\
Stratocumulus (Sc) & 12 & 22 & & 1000 & 600 \\
Cumulus (Cu) & 5 & 13 & & 1100 & 600 \\
Cumulonimbus (Cb) & 4 & 6 & & 1000 & 500 \\
Nimbostratus (Ns) & 5 & 5 & & \\
Altostratus (As) & 4 & 6 & & \\
Altocumulus (Ac) & 17 & 17 & & \\
High (cirriform) & 22 & 12 & & & \\
Total cloud cover & 54 & 68 & & & \\
Clear sky (frequency) & 22 & 3 & &
\end{tabular}

can be obtained as the product of frequency-ofoccurrence (fraction of weather observations in which a cloud of this type is present, whether visible or hidden) and amount-when-present (the average fraction of the sky covered by this cloud type when it is present, whether visible or hidden). For example, if cumulus is present in $30 \%$ of the weather observations from a station, and if it covers on average $40 \%$ of the sky when it is present, then the average amount of cumulus at that station is $12 \%$.

The amount, or even the presence, of a middle or high cloud may be indeterminate when a lower cloud nearly or completely covers the sky. The average amounts of middle and high cloud types can be estimated by assuming that the frequency and amountwhen-present are the same in observations where they cannot be calculated as in observations where they can be calculated. To obtain amount-when-present of upper clouds, the clouds at different levels are assumed to be randomly overlapped. These assumptions, and their justification, are discussed by Warren et al. $(1986,1988)$ and Norris (2005a, section 2.4). More detail about the method is given by Hahn and Warren (2003).

\section{Considerations of criteria for trend analysis}

a. Changes in observing procedures limiting the period of record to be analyzed

The synoptic code was defined by the International Meteorological Organization in 1929, to be used world- wide beginning in 1930 (NCDC 1962). However, the code assignments of the cloud types were changed in 1949, and also at that time the coding of cloud amount was changed from tenths to eighths. (In some countries weather observations are still made in tenths for a nation-specific reporting code but are reported in eighths in the synoptic code.) We find that the changes in reporting of cloud types in the ocean stabilized in about 1954. For the land areas we have a further restriction that global coverage is not available until 1971; that is why our land climatology begins in 1971. The reports in nation-specific codes are archived by national meteorological centers in those countries and often have longer periods of record than we analyze here. The various nation-specific codes for cloud types may be mutually incompatible, but total cloud cover is included in all the codes. Regional studies of cloud trends are therefore possible for a number of countries with records extending back prior to 1971, and several have been published as cited above, but in the early years often only the monthly averages of total cloud cover are available. Where those studies overlap in time with ours, the results are generally in agreement. For example, a comparison of the interannual variations in cloud cover from the national archives of the United States, China, and the Former Soviet Union, to those obtained from our dataset, showed good agreement (Fig. 5 of Sun and Bradley 2002). However, in the 1930s and 1940s (prior to the beginning of our dataset) there are strange variations of reported total cloud cover that are probably due to nonclimatic causes (e.g., Karl and Steurer 1990).

Beginning in 1982, the cloud-types section of the report became optional if there are no clouds, and the present-weather code also became optional if there is no "significant" weather. This change affects the computation of the frequency-of-occurrence of cloud types. We have been able to take this change into account in our analysis procedure, either by the methods of Norris (1998) and Hahn and Warren (1999) for the ocean, or in the case of land data, by rejecting stations that do not normally report cloud types (Hahn and Warren 2003).

\section{b. Examples of trend computation}

Time series of cloud amounts were analyzed for each of the 5388 stations, for day and night separately, for each of four seasons, for total cloud cover and nine different cloud types, a total of about 430000 plots. Some examples are shown in Fig. 2 for six of the stations, comparing day and night. These plots are all for total cloud cover (the seasonal average fraction of the sky-hemisphere covered by cloud). Linear fits were made using both the least squares method and the me- 

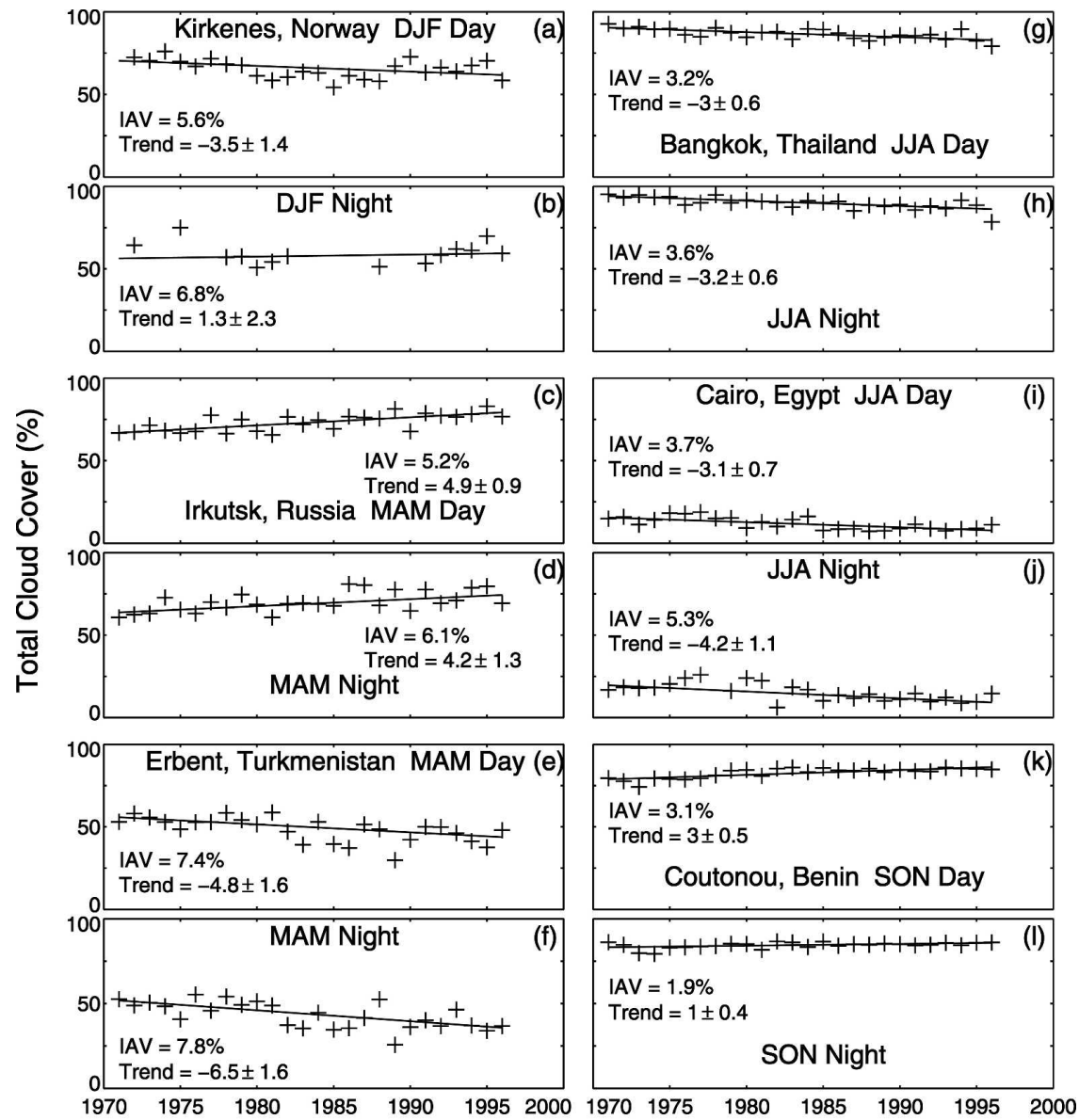

\section{Year}

FIG. 2. Seasonal values of average total cloud cover for day and night separately, for each of six selected stations from 1971 to 1996 . For these plots, "day" is defined as 0600-1800 local time, and all observations made between these hours are used. (The reporting is usually done at intervals of 3 or $6 \mathrm{~h}$, but there can be missing observations.) The seasons are DJF, MAM, JJA, and SON. The WMO identification numbers for these stations are Kirkenes 01089, Irkutsk 30710, Erbent 38656, Bangkok 48455, Cairo 62366, and Coutonou 65344.

dian-of-pairwise-slopes method (Lanzante 1996). The two methods were almost always in very close agreement. The median-of-pairwise-slopes method is less influenced by outliers, so it is used in the results presented here. (We express changes of cloud cover in units of percentage points, or "absolute percent." For example, if a seasonal average cloud amount changed from $13 \%$ to $12 \%$, we report the change as $-1 \%$.)

There is much interannual variation to be explained, and usually an overall trend. Of course, the trends can represent only this $26-y r$ period, and in many cases may be altered significantly when more years are added. Included in Fig. 2 are examples of large cloud amount (above $80 \%$ for Bangkok, Thailand, in summer), small cloud amount (less than $20 \%$ for Cairo, Egypt, in summer), both decreasing and increasing trends, and ex- amples of both large and small interannual variations (IAVs). In many cases a linear trend does appear to be a good description of the data. One counterexample is Kirkenes, on the Arctic coast of Norway (Figs. 2a,b), whose winter climate is influenced by the Northern Annular Mode (NAM); its IAVs are positively correlated with an index of the NAM, as will be shown below. The cloud cover was large in the 1970s, small in the 1980s, then large again in the 1990s, generally following the NAM index.

\section{c. Nighttime observations}

Kirkenes also illustrates a problem with the data availability, in that several years are missing for night (Fig. 2b). Some stations make fewer observations at night than during the day. In addition, because of the 
moonlight criterion we are able to use only about $38 \%$ of the observations made with the sun below the horizon. For Fig. 2 we plotted a point in a particular year only if the season had at least 75 observations (daytime) or 50 observations (night). At the five other stations in Fig. 2, the nights are well represented, and it is apparent that the night trends are similar to the day trends. This agreement suggests that we might use the day trends to represent the cloud trends at stations that lack adequate nighttime observations.

Figure 3 is a test of this idea, plotting the night trend versus the day trend for the December-February (DJF, hereafter 3-month periods are denoted by the first letter of each respective month) season. Each point is one station. To reduce the clutter, we plot only every twentieth station (of the stations that satisfied our criteria for trend analysis). Figure 3 shows that the correlation is good for total cloud cover and for all the cloud types except cumulus. (Fog also shows poor correlation, but this is just because most of the trends are near zero.) However, where day trends differ from night trends they could indicate significant changes in cloud radiative forcing. In future work it will be interesting to examine the geographical patterns of the differences between day trend and night trend in regions where both are reliably determined.

\section{d. Number of observations required to represent a seasonal mean}

Most stations give weather reports either 4 or 8 times per day, at UT hours divisible by 6 or 3. If the observations are reliably transmitted via the Global Telecommunications System (GTS) to the archiving locations, the maximum possible number of observations per season would be $4 \times 91=364$ in daytime, and about 140 at night because of the additional requirement for adequate lunar illuminance. If fewer observations are available, the seasonal mean is represented less accurately. The sampling error as a function of the number of observations was determined from a statistical study by Warren et al. (1986, their Fig. 5), who found that the expected error in seasonal mean cloud cover at land stations was $3 \%$ if 200 observations were averaged.

For a trend, the reliability also depends on the number of years used to compute it. The average uncertainty in the slopes of the trend lines (for all stations) is plotted in Fig. 4a as a function of the number of years, with two alternative criteria for the number of observations required per year-season. The uncertainty drops rapidly to $15 \mathrm{yr}$ (of the 26 available years), then more slowly, and beyond $15 \mathrm{yr}$ it appears that $75 \mathrm{ob}-$ servations per season are adequate.
Figure $4 \mathrm{~b}$ shows the number of stations meeting these requirements, illustrating the trade-off between accuracy of trends and coverage of the continents. Based on Fig. 4, we compute a daytime trend for a season if we have a minimum of 75 observations in each of at least $15 \mathrm{yr}$, spanning at least $20 \mathrm{yr}$. For night we require 50 observations. Figure $4 \mathrm{~b}$ shows that we can expect our global maps of trends to have much better areal coverage for the daytime than for night. Because night trends are similar to day trends (Fig. 3), and because we are not focusing here on the small differences between them, in the remainder of this paper we will show trends only for daytime cloud amounts (0600 1800 local time). We display a trend if it exceeds its uncertainty, or if the uncertainty is less than $2 \%$ decade $^{-1}$.

\section{e. Combining trends from stations within a grid box}

A grid box on land may contain several stations in different topographic regions, with correspondingly different cloud climatologies. If one station began observations halfway through the period of record, an apparent but spurious trend would result if all observations in the grid box for a given year were grouped together. We therefore first perform a trend analysis for each individual station. If a grid box contains more than one station, we average their trends.

\section{f. Stations giving erroneous or biased records}

For some stations, the trend analyses led to detection of erroneous or biased reports that we had not noticed in our maps of long-term average cloud amounts. After investigation, we removed a few stations from our analyses. The largest set of stations giving erroneous trends was a string of military stations along latitude $69^{\circ} \mathrm{N}$ across Alaska and Canada, the Distant Early Warning (DEW) Line. Large positive trends of nimbostratus were found for many of these stations. Apparently after their staffing was reduced in 1985-86, many of the DEW Line stations began reporting an erroneous present-weather indicator when there was no significant weather to report, with the result that nimbostratus became overrepresented in recent years. We do not use these stations in our trend analyses, but they have not yet been removed from our digital database (Hahn and Warren 2003).

\section{Global distribution of trends}

Figure 5a shows the slopes of trend lines for total cloud cover, in units of $0.1 \%$ decade $^{-1}$. A trend was computed for each station; then the trends were aver- 


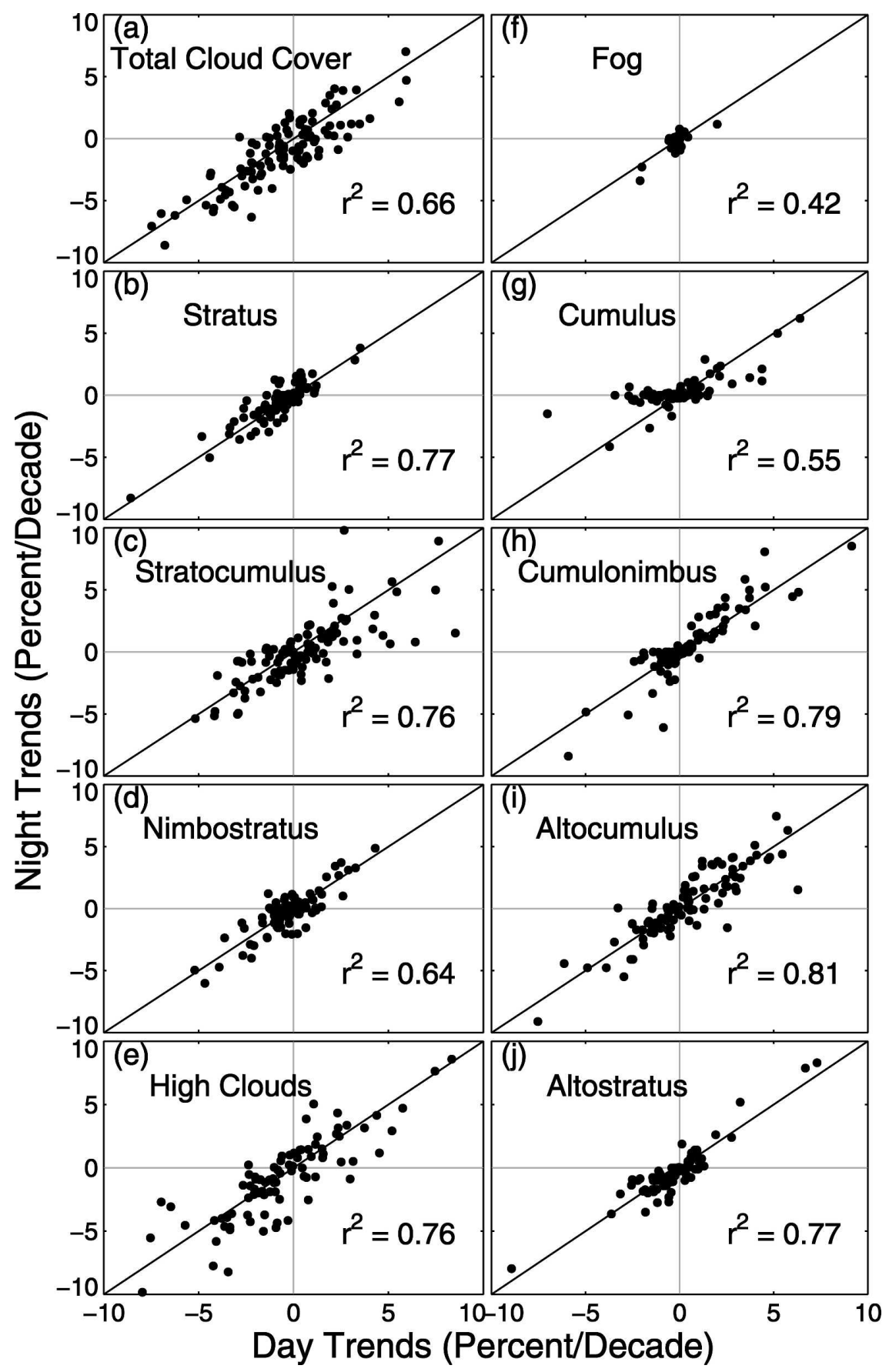

FIG. 3. Relation of nighttime trend to daytime trend, DJF 1971-96. Each point is one station. To reduce clutter, only every twentieth station is plotted (of the 2094 stations that satisfied criteria for computing trends both day and night). The correlation value $\left(r^{2}\right)$ is also given.

aged for all stations in a $10^{\circ} \times 10^{\circ}$ latitude-longitude box. For Fig. 5a we further averaged the trends for the four seasons to obtain the annual average.

The continents are well represented, as well as many islands. (The values in the ocean areas come only from weather stations on islands; the ship observations from these boxes will be separately analyzed in future work.) Zonal average trends were computed, weighting the boxes by their land fractions. They are listed along the right side of the maps. The global average trend is an 


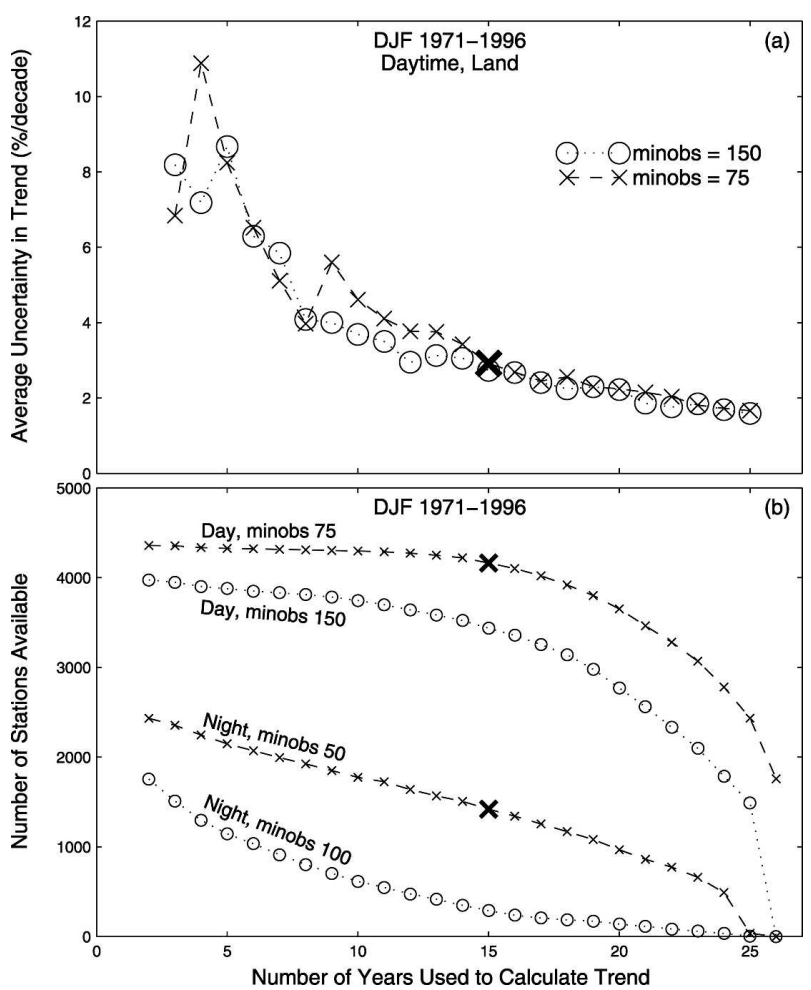

FIG. 4. (a) Average uncertainty in slope of linear trend line of total cloud cover, as a function of the number of years used to calculate the trend. The average is over all stations having sufficient numbers of observations ("minobs") for each of the years used to calculate the trend. Two values of minobs are used. The bold $\mathrm{X}$ indicates the criterion selected for the daytime trend analyses in this paper: minobs $=75$, minimum number of years ("minyr") $=15$. (A minimum span of $20 \mathrm{yr}$ is also required.) (b) The number of stations satisfying various criteria of minobs and minyr, with the selected criteria indicated by a bold $\mathrm{X}$.

average of the zonal trends, weighted by their land areas, but excluding the Antarctic region $\left(60^{\circ}-90^{\circ} \mathrm{S} ; 9 \%\right.$ of the global land area) because of its poor sampling in space and time. Negative trends dominate over most of the globe except $60^{\circ}-80^{\circ} \mathrm{N}$. The global average trend for land areas, given in Fig. 5a, is $-0.7 \%$ decade $^{-1}$. Analysis of the ship observations in the EECRA for 1952-95 gave a small positive trend over the ocean, $+0.4 \%$ decade $^{-1}$ (Norris 1999). The global cloud cover (land + ocean) therefore shows almost no trend. This result agrees with the lack of global trend found in satellite analyses of Wylie et al. (2005) from the highresolution infrared sounder (HIRS) for 1979-2001 and disagrees with the negative global trend of the International Satellite Cloud Climatology Project (ISCCP; Fig. $4 \mathrm{~d}$ of Rossow and Dueñas 2004). The negative trend of ISCCP may be partly explained by artifacts in the geostationary satellite data (Campbell 2004; Norris 2005a, paragraph 22).
In Figs. 5b and 5c we show maps of trends for two of the cloud types, one (cirriform, DJF) that contributes substantially to the negative global trend of total cloud cover and one that does not (cumulonimbus, JJA). Wintertime cirrus shows widespread negative trends over Eurasia and North Africa. In summer, cumulonimbus amount has apparently increased over Siberia and central Asia, but decreased over China and much of the United States. We will examine trends over China in more detail below.

Figure 5 shows a small sample of the maps we have examined. Maps were made for each of the nine cloud types as well as clear-sky frequency; for day, night, and combined day plus night; for four seasons; and for cloud frequency, amount-when-present, and amount (and nonoverlapped amount and base height where applicable), a total of about 400 maps. (The trends for cloud amounts and base heights are available on our Web site.) The 400 maps were examined for outliers, and the outliers were investigated by plotting time series for individual stations in the box. This process led to the identification of a few stations whose reports were judged unreliable, so they were excluded from subsequent analyses.

Figure 6 shows time series of seasonal anomalies of total cloud cover for the continents. These were obtained by averaging the anomalies in each $10^{\circ} \times 10^{\circ}$ box, weighting the boxes according to their size (a function of latitude) and their fractional land areas. The IAVs (standard deviations of the seasonal anomalies) are also given. Slight negative trends are found for Eurasia and Africa and no trend for North America. South America has the largest overall trend. Australia (and the Pacific Islands) has the largest IAV, most likely because of its small size and because it is greatly influenced by the El Niño-Southern Oscillation (ENSO). The negative trend in this region is probably related to a documented increase in surface divergence in recent decades (Norris 2005b).

For South America, and perhaps also Africa and Australia, Fig. 6 seems to show some indication of the climatic shift of 1976/77 (Deser et al. 2004). The interannual variations on these three continents are strongly affected by ENSO, and the evolution of El Niño was different before and after the shift (Trenberth and Stepaniak 2001; Trenberth et al. 2002). We will examine ENSO correlations below.

We have also computed time series of total cloud cover for the Northern Hemisphere land and Southern Hemisphere land (not shown); they agree with those presented by Dai et al. (2006) for the years in common to both analyses (1975-96). In particular, Dai et al. (their Fig. 1a) find that the global average land cloud 




FIG. 5. Linear trends of cloud amounts, in units of $0.1 \%$ decade $^{-1}$, for $1971-96$, for $10^{\circ} \times 10^{\circ}$ grid boxes. (The longitudinal extent of the boxes is greater at high latitudes to maintain approximately equal areas for the boxes: $10^{\circ} \times 20^{\circ}$ for $50^{\circ}-70^{\circ}$ latitude, $10^{\circ} \times 40^{\circ}$ for $70^{\circ}-80^{\circ}$, and $10^{\circ} \times 120^{\circ}$ for $80^{\circ}-90^{\circ}$.) Trends were obtained for each weather station; then the trends were averaged for all stations within a grid box. Negative trends are italicized. The values in oceanic regions are from island stations, not ships. Values are plotted if the trend is greater than its uncertainty, or if the uncertainty is less than $2 \%$ decade $^{-1}$. Zonal averages are listed off the right side of each map; they are formed by averaging the gridbox values, weighted by the land fraction in each box. The global average given in the legend is a weighted average of the zonal values, weighted by land fraction and zonal area, excluding the poorly sampled region $60^{\circ}-90^{\circ} \mathrm{S}$. (a) Total cloud cover; average of four seasons. (b) High clouds in DJF. (c) Cumulonimbus in JJA.

cover decreased from 1975 to 1996, as we do. For their global analyses (excluding the United States and Canada) Dai et al. used synoptic cloud reports as a data source, as we do, but they used approximately 11000 stations rather than our selected subset of 5388 stations. The agreement of our hemispheric average anomalies implies that they are not highly sensitive to the criteria used for selecting stations, at least for total cloud cover.

The global average trends for each cloud type are listed in Table 3. The low cloud types show a decrease in stratus (St) that is partly compensated by increases in stratocumulus $(\mathrm{Sc})$, cumulus $(\mathrm{Cu})$, and cumulonimbus 


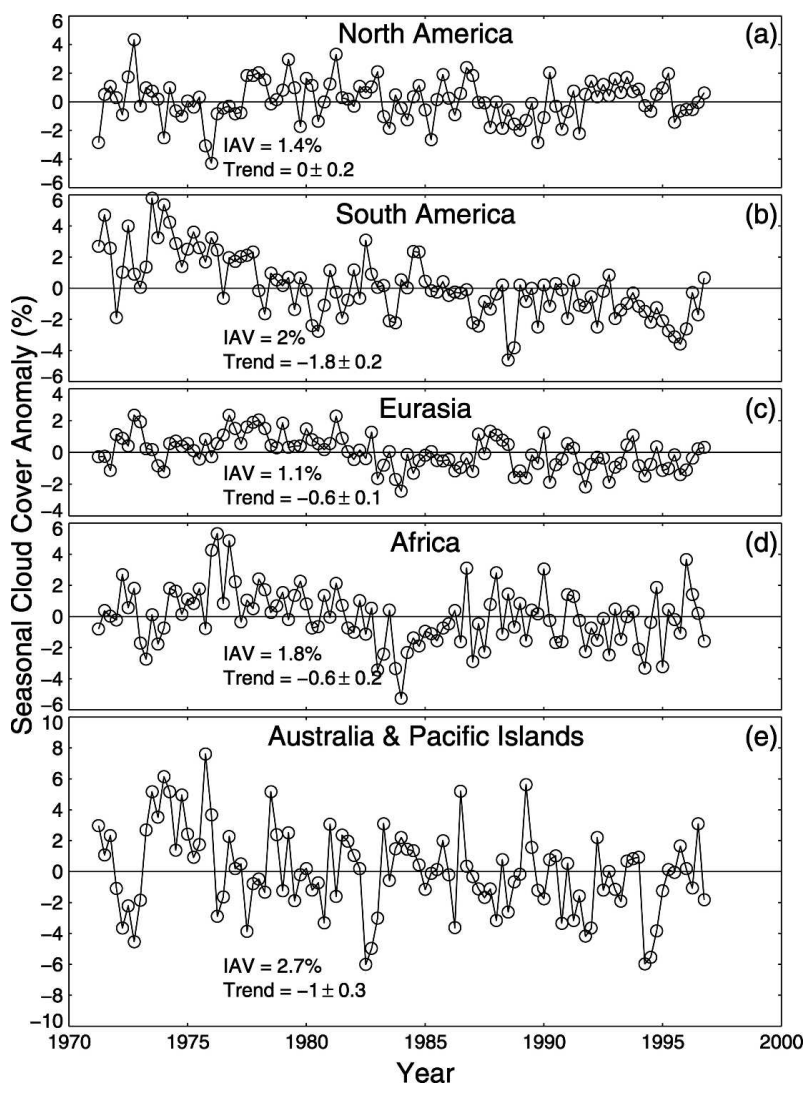

FIG. 6. Time series of seasonal anomalies of total cloud cover for five continents. Seasonal anomalies were obtained for each station, relative to the long-term mean for that station for that season. The station anomalies were averaged within each $10^{\circ} \times$ $10^{\circ}$ grid box; then all the grid boxes within a continent were averaged, weighted by their land areas. Interannual variations (standard deviation of the seasonal anomalies) and linear trends are given in the legends. The tick marks on the horizontal axis are at the season DJF.

$(\mathrm{Cb})$, suggesting a slight increase in convective activity. There is a similar compensation in the middle clouds, with altocumulus (Ac) amount increasing while altostratus (As) and nimbostratus (Ns) decrease. Table 3 also shows that high clouds are the major contributor to the negative trend in total cloud cover. An independent study by Norris (2005a) using the EECRA found that upper cloud amount (overlapped middle + high) over land, $30^{\circ} \mathrm{S}-60^{\circ} \mathrm{N}$, decreased by $0.6 \%$ decade $^{-1}$, in substantial agreement with Table 3 .

The zonal average trends of total cloud cover (for land areas only) are plotted as a function of latitude in Fig. 7. Values for each season are shown, as well as the average of the four seasons. (The average of the four seasons is the same value shown along the right side of Fig. 5a.) It is apparent that negative trends dominate. The major exception is in the Arctic winter and spring $\left(60^{\circ}-80^{\circ} \mathrm{N}\right)$. This region has been warming faster than
TABLE 3. Global average trends of daytime cloud-type amounts (for land areas only), 1971-96. The units are in \% decade ${ }^{-1}$. The sum of the trends for types does not equal the trend for total cloud cover because of overlap (and possible trends in overlap).

\begin{tabular}{lrrrrr}
\hline & DJF & MAM & JJA & SON & Annual \\
\hline Fog & -0.2 & -0.1 & 0.0 & -0.1 & -0.1 \\
Stratus (St) & -0.4 & -0.4 & -0.3 & -0.5 & -0.4 \\
Stratocumulus (Sc) & 0.1 & 0.1 & 0.1 & 0.1 & 0.1 \\
Cumulus (Cu) & 0.2 & 0.0 & 0.0 & 0.1 & 0.1 \\
Cumulonimbus (Cb) & 0.2 & 0.1 & 0.0 & 0.1 & 0.1 \\
Nimbostratus (Ns) & -0.2 & -0.2 & -0.2 & -0.3 & -0.2 \\
Altostratus (As) & -0.4 & -0.4 & -0.2 & -0.3 & -0.3 \\
Altocumulus (Ac) & 0.2 & 0.3 & 0.2 & 0.2 & 0.2 \\
High (cirriform) & -0.7 & -0.7 & -0.5 & -0.5 & -0.6 \\
Total cloud cover & -0.6 & -0.7 & -0.7 & -0.9 & -0.7 \\
Clear sky (frequency) & 0.5 & 0.3 & 0.2 & 0.7 & 0.4 \\
\hline
\end{tabular}

the global average in the past $25 \mathrm{yr}$ (Houghton et al. 2001, their Fig. 2.9d). It will therefore be interesting to monitor cloud changes in the future in this region. The trends in Fig. 7 for Arctic land are positive in winter but negative in summer. This is opposite to the findings of Wang and Key (2003) for satellite-inferred cloud cover for the period 1982-99. However, their plots are for the entire zone $60^{\circ}-90^{\circ} \mathrm{N}$, not separating land and ocean, so further work is needed to make a definitive comparison. Our preliminary analysis for the central Arctic Ocean (section 8 of Hahn et al. 1995) finds a positive trend in winter, in agreement with our Arctic land trend.

A possible explanation for the positive trend in Arctic cloud cover in winter is that climatic warming would make it more difficult for liquid droplets to freeze; liq-

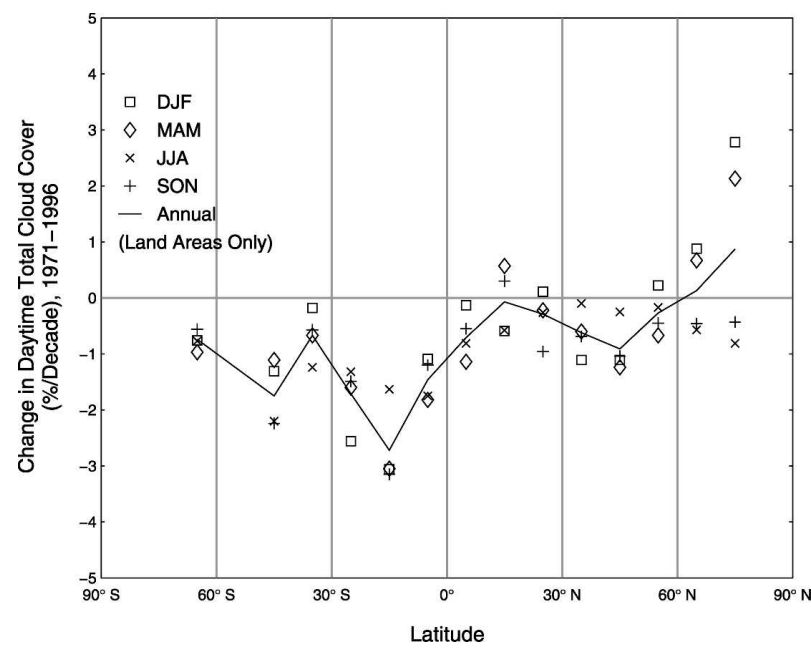

FIG. 7. Zonal trends of total cloud cover, computed as described in the caption of Fig. 5, as a function of latitude, for four seasons, 1971-96. The solid line is the average of the four seasons, also given numerically along the right side of Fig. 5a. 


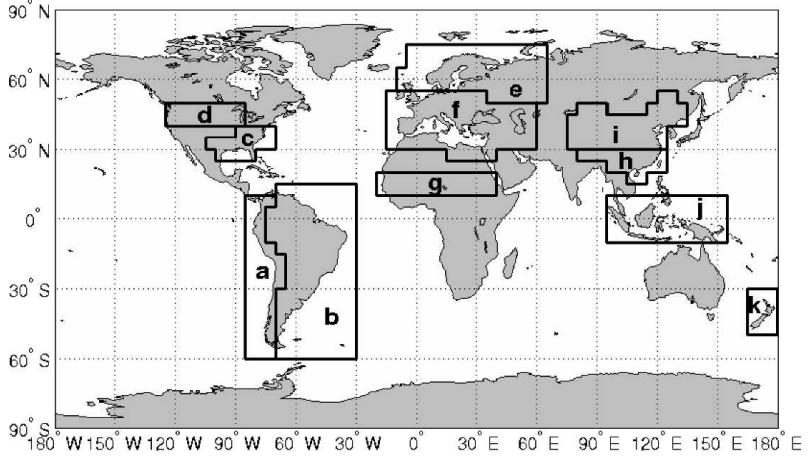

FIG. 8. Regions used for the trend analyses shown in Table 4. (Only the land areas within these regions are analyzed.)

uid water clouds have longer lifetimes than glaciated clouds (Pinto 1998; Beesley and Moritz 1999).

\section{Regional trends}

Significant trends are found for particular cloud types in different regions of the globe. They are geographically coherent across national boundaries and often large, so they invite explanations as real climatic changes rather than changes in reporting procedures. They are all displayed on the maps on our Web site. Average trends for some selected large regions (defined in Fig. 8) are given in Table 4. From this table the trend in total cloud cover can be attributed to particular cloud types. For example, the negative trends in western South America are mostly due to Ac and high clouds, but in eastern South America all types except $\mathrm{Cu}$ contribute to the negative trend. In the United States, the northwest and southeast exhibit opposite trends of total cloud cover, and it is mostly middle and high clouds that are responsible for the difference. The Sahel shows a reduction in the precipitating cloud, $\mathrm{Cb}$, but a stronger increase in high clouds caused the total cloud cover to increase.
We show some of the trends in geographical detail here for just one region, East Asia, in Fig. 9 at $2.5^{\circ} \times$ $2.5^{\circ}$ resolution. A strong negative trend of cloud cover has previously been reported for China from surface observations obtained directly from the Chinese Meteorological Administration for the periods 1951-96 (Kaiser 1998, 2000) and 1955-2000 (Qian et al. 2006). In Fig. 9a we confirm their finding for the period 1971-96 and show that it extends beyond the boundaries of China into neighboring countries. The example shown is for winter (DJF), but all seasons show an overall negative trend. Cirrus is a major contributor to the negative trend, primarily in the north in DJF (Fig. 9b) and in the south in JJA (Fig. 9c). The other major contributor to the negative trend in total cloud cover is Ac, but $\mathrm{St}, \mathrm{Ns}, \mathrm{Cu}$, and $\mathrm{Cb}$ also contribute, as shown in Table 4. In fact, the only cloud type that shows an overall positive trend is Sc (Table 4), shown in Fig. 9d for spring (MAM), the season with the strongest Sc trend.

We do not yet have explanations for these trends over East Asia. As one possibility, Krüger and Grassl (2004) presented evidence from a near-infrared satellite channel that absorbing aerosols have caused reductions in low-level and middle-level cloud cover over southeast China (presumably by heating and evaporating cloud droplets). However, in the case of high clouds we caution that some of the trends could be artificial. Of all the cloud types, cirrus has the smallest optical thickness, and it can be difficult to detect above a thick haze in the boundary layer. The negative trend in reported cirrus in summer across India, Bangladesh, Myanmar (Burma), and south China might partly have been caused by an increase in aerosol haze, as the human populations in all these regions grew. Emissions of aerosol precursors in South Asia have increased about six fold since 1930 (Ramanathan et al. 2005), and atmospheric visual range has correspondingly decreased (Kaiser and Qian 2002). In north China the cirrus may

TABLE 4. Regional trends (\% decade ${ }^{-1}$ ) of annual average daytime cloud-type amounts (for land areas only), 1971-96. The sum of the trends for types does not equal the trend for total cloud cover ("total") because of overlap (and possible trends in overlap). Boundaries of these regions are indicated in Fig. 8, identified by (a)-(k).

\begin{tabular}{|c|c|c|c|c|c|c|c|c|c|c|}
\hline & Fog & St & Sc & $\mathrm{Cu}$ & $\mathrm{Cb}$ & Ns & As & Ac & High & Total \\
\hline South America west coast (a) & -0.1 & -1.0 & -0.3 & 0.8 & -0.2 & -0.3 & 0.5 & -2.1 & -2.8 & -1.6 \\
\hline South America east coast and interior (b) & -0.1 & -0.3 & -1.3 & 0.4 & -0.3 & -0.1 & -0.5 & -1.2 & -1.2 & -2.2 \\
\hline Southeast United States (c) & -0.1 & -0.3 & 0.6 & -0.5 & -0.2 & 0.0 & -0.1 & 0.7 & 1.5 & 0.6 \\
\hline Northwest United States (d) & -0.0 & -0.3 & 0.8 & -0.4 & -0.2 & -0.3 & -0.4 & 0.3 & -0.2 & -0.6 \\
\hline Northwest Eurasia (e) & -0.2 & -1.1 & 0.2 & -0.3 & 1.0 & -0.8 & -0.1 & 1.9 & -0.6 & 0.4 \\
\hline Mediterranean and east (f) & -0.1 & -0.5 & -0.6 & 0.3 & 0.2 & -0.3 & -0.3 & 0.5 & -0.9 & -0.9 \\
\hline Sahel $(\mathrm{g})$ & 0.0 & -0.0 & 0.2 & -0.0 & -0.4 & 0.0 & -0.2 & -0.0 & 0.9 & 0.3 \\
\hline China south of $30^{\circ} \mathrm{N}(\mathrm{h})$ & -0.0 & -0.7 & 2.0 & -0.3 & -0.4 & -0.0 & -0.2 & -0.8 & -2.4 & -0.6 \\
\hline China north of $30^{\circ} \mathrm{N}(\mathrm{i})$ & 0.1 & -0.4 & 0.4 & -0.0 & -0.1 & -0.0 & -0.1 & -1.4 & -0.8 & -1.4 \\
\hline Indonesia and New Guinea (j) & -0.1 & -0.8 & -0.3 & 2.1 & 0.8 & -0.3 & 0.4 & 1.5 & 0.1 & 0.4 \\
\hline New Zealand (k) & 0.0 & 0.0 & 0.9 & -0.6 & -0.1 & -0.2 & -0.2 & 0.0 & -1.9 & -0.6 \\
\hline
\end{tabular}


(a) Trend of Total Cloud Cover, D.JF

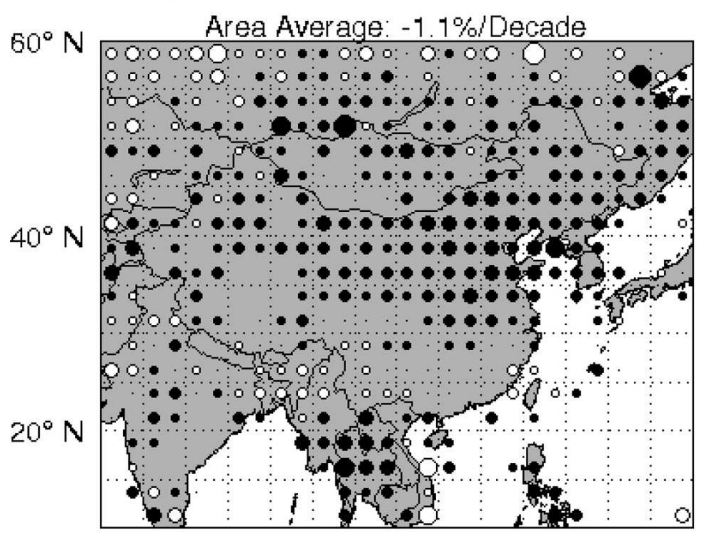

(c) Trend of High Cloud Amount, JJA

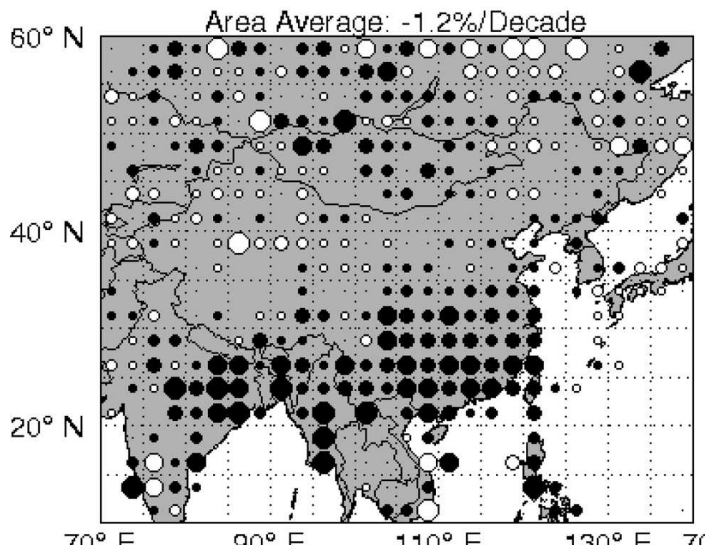

$\begin{array}{llllll}70^{\circ} \mathrm{E} & 90^{\circ} \mathrm{E} & 110^{\circ} \mathrm{E} & 130^{\circ} \mathrm{E} & 70^{\circ} \mathrm{E}\end{array}$ (b) Trend of High Cloud Amount, D.JF

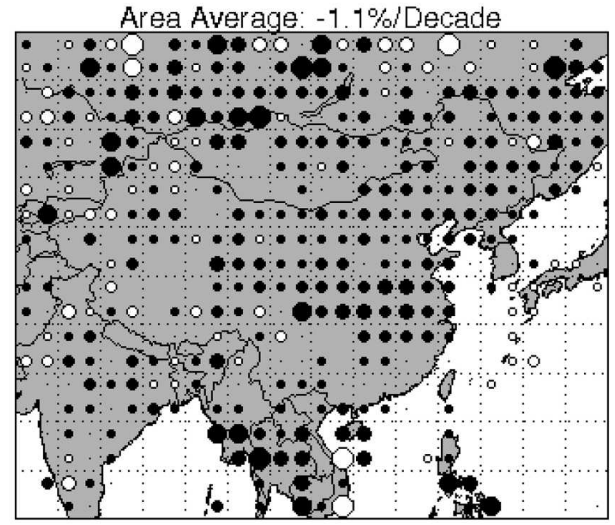

(d) Trend of Stratocumulus Amount, MAM

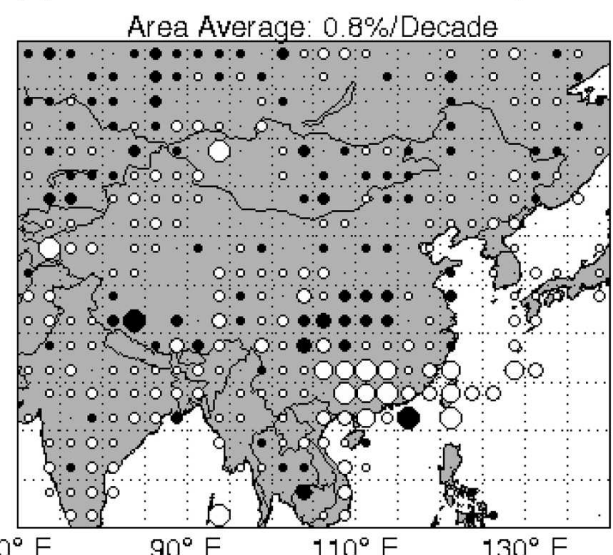

$0 \geq 8$

○ 6 to 8

- 4 to 6

- 2 to 4

- 0.5 to 2

$\cdot 0.5$ to -0.5

- -0.5 to -2

- -2 to -4

- -4 to -6

- -6 to -8

$\leq-8$

FIG. 9. Linear trends of cloud amounts in East Asia, for $2.5^{\circ} \times 2.5^{\circ}$ grid boxes, 1971-96. The size of each dot indicates the magnitude of the trend; the units are percent per decade.

be obscured by atmospheric dust, particularly in spring. However, the frequencies of dust storms and dust haze in north China have decreased since 1970 (Qian et al. 2002, 2004; Zhao et al. 2004; Wang et al. 2004), so dust obscuration cannot be responsible for our cirrus trends in this region.

\section{Cloud variations associated with modes of atmospheric circulation}

\section{a. Nimbostratus and the Northern Annular Mode}

Figure 10 shows the trends of total cloud cover (in $2.5^{\circ}$ grid boxes) over Europe in winter. A regionally coherent negative trend is found in western Europe, strongest over the Mediterranean region, and consistent with the negative trends for 1951-96 at Italian stations reported by Maugeri et al. (2001). Positive trends are found over Russia and Norway. However, examination of the time series shows that these trends are by no means monotonic; the IAV is large, and the "trend" is sensitive to the starting and ending dates of the period of record chosen for computing a trend. The dominant cause of cloud variability in this region is the North Atlantic Oscillation (NAO), or its close relative, the NAM (Thompson and Wallace 2000). The NAM index became more positive during the time span of our analysis (1971-96). The seasonal cloud cover anomalies for the land areas around the Mediterranean (boxed region in Fig. 10) are plotted in Fig. 11 versus the NAM index, showing a strong negative correlation. The cloud type showing the strongest correlation is nimbostratus, and in Fig. 12 we plot values of the correlation coefficient of Ns with the NAM index. The pattern of negative correlation across western Europe, but positive correlation in Iceland, Scotland, and Norway, is consistent with the pattern seen upstream in the Atlantic Ocean using ship observations from the EECRA (Park and Leovy 2000). Figure 12 corresponds well to the 


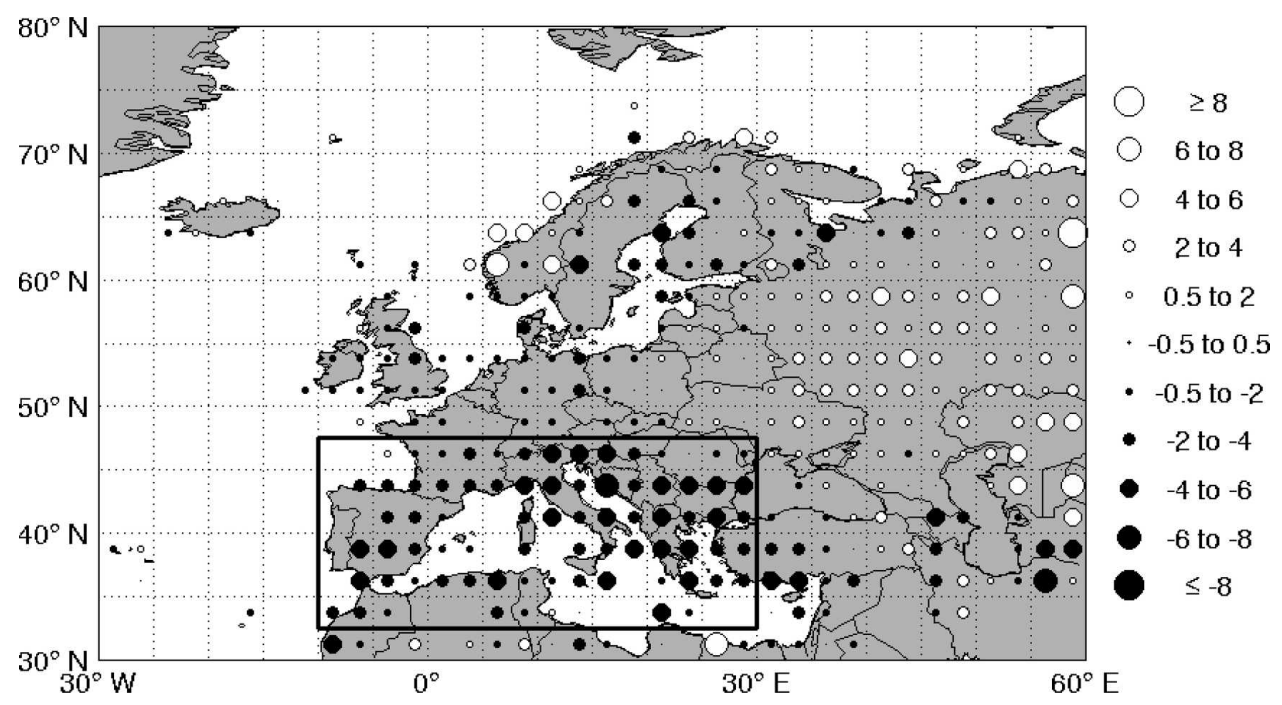

FIG. 10. Linear trends of total cloud cover for $2.5^{\circ} \times 2.5^{\circ}$ boxes in Europe and North Africa, for DJF, 1971-96. The boxed region is used for the analysis shown in Fig. 11.

correlations of winter precipitation with the NAO at European stations shown in Table 1 of Hurrell (1995). Clouds predicted by the NCEP reanalysis also show these correlations with the NAO (Trigo et al. 2002).

\section{b. El Niño and the Southern Oscillation}

Correlations of seasonal mean cloud cover with an ENSO index are shown in Fig. 13. [The ENSO index

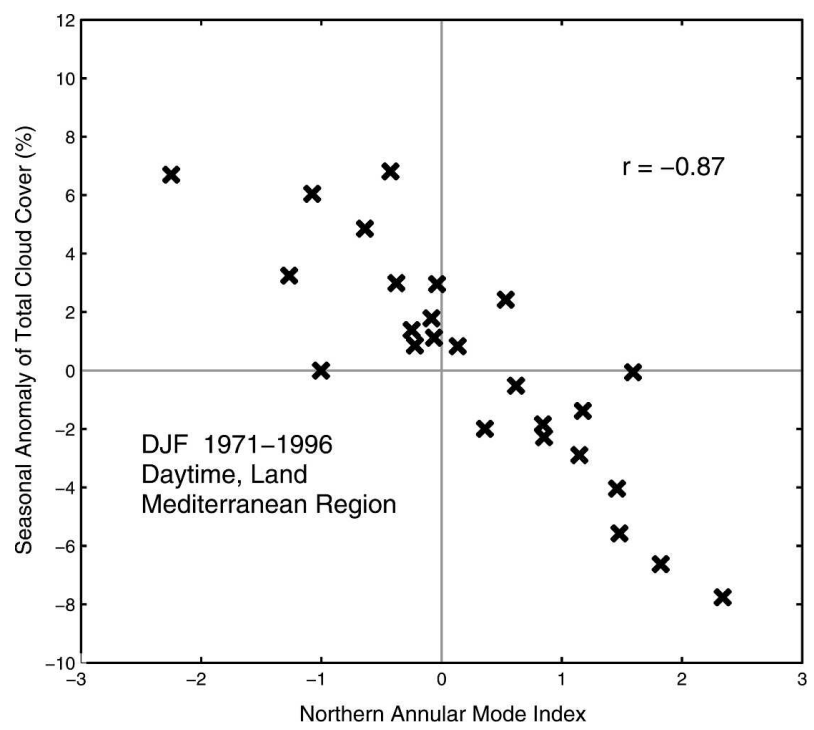

FIG. 11. Correlation of winter season cloud cover anomalies with an index of the NAM for the Mediterranean region outlined in Fig. 10. Seasonal anomalies were obtained for each station, relative to the long-term mean for that station for that season. The station anomalies were averaged within each $10^{\circ} \times 10^{\circ}$ grid box; then all the grid boxes within the Mediterranean region were averaged, weighted by their land areas. was produced by the Japanese Meteorological Agency, using the methods of Meyers et al. (1999); we obtained it from ftp://www.coaps.fsu.edu/pub/JMA_SST_Index/.] El Niño conditions are associated with less cloud cover in Indonesia, Southeast Asia, southern Africa, and the Amazon basin, with greater cloud cover over islands of the central equatorial Pacific. Figure 14 shows how seasonal anomalies of the precipitating clouds (the sum of $\mathrm{Cb}$ and Ns amounts) correlate with ENSO; here the correlations are more seasonally dependent than for total cloud cover, showing for example that the ENSOinduced reduction in precipitating clouds in southern Africa is prominent only in the wet season (DJF). Positive correlations of $\mathrm{Cb}+\mathrm{Ns}$ with the ENSO index are found in Ecuador and Peru in DJF and MAM as expected, and in Mexico and the southern United States.

Globally, El Niño has been shown to cause increases in precipitation over the ocean and decreases over land (Trenberth and Shea 2005; Trenberth et al. 2002). As the frequency of El Niño conditions increased from 1971 to 1996, a decrease of land cloud cover and an increase of ocean cloud cover may be expected, as we indeed observe. However, at the global scale the correlations are weak: we find that seasonal anomalies of global land cloud cover correlate with the ENSO index with $r=-0.12$; the correlation for global ocean cloud cover is $r=+0.13$.

\section{Anthropogenic influences on cloud formation}

\section{a. Condensation trails from aircraft}

Condensation trails ("contrails") sometimes dissipate quickly, but if the upper-tropospheric humidity (UTH) 
DJF (1971-1996)

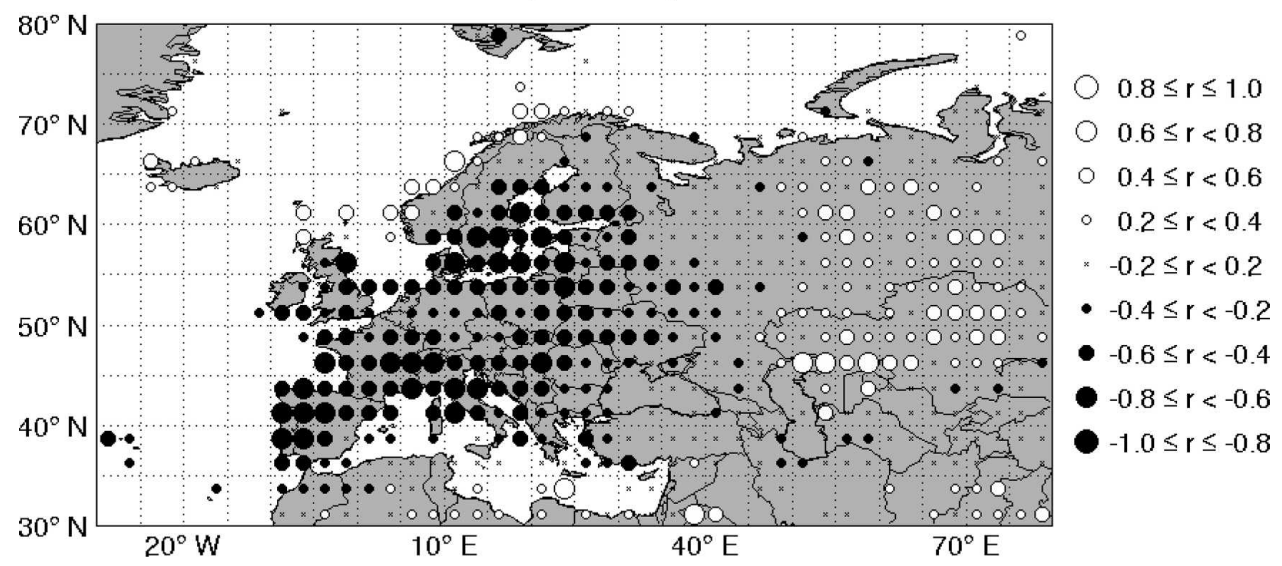

FIG. 12. Correlation of nimbostratus anomalies with the NAM index, for $2.5^{\circ} \times 2.5^{\circ}$ boxes in Europe and North Africa, for DJF, 1971-96. The size of each dot indicates the magnitude of the correlation coefficient $r$.

is sufficient, they can spread out to become cirrus clouds. Boucher (1999) used visual cloud reports from an early version of our EECRA and found increasing cirrus amounts in regions of flight paths. A more comprehensive study by Minnis et al. (2004) used the same version of the EECRA that we are analyzing in this paper (for 1971-96) and compared trends in cirrus to trends in UTH. They found an increase in cirrus over the United States, no change over Europe (increasing contrails apparently compensating for a reduced UTH), and a decrease over other land areas. Our Fig. 5b shows cirrus trends for just the DJF season. In western Europe the trends are negative in DJF and MAM but positive in JJA and SON (not shown), giving essentially no trend for the annual average, as Minnis et al. found.

Although contrails are detectable both from the surface and from satellite, at present they appear to have only small effects on the radiation budgets (Stubenrauch and Schumann 2005; Shine 2005).

\section{b. Smoke aerosols}

There are many possible effects of aerosols on clouds. Because cloud droplets nucleate on aerosol particles, an increase in soluble aerosols (cloud condensation nuclei) can lead to a larger number of smaller droplets and therefore longer cloud lifetimes (e.g., Charlson et al. 1992). On the other hand, dark aerosols that absorb sunlight may cause clouds to evaporate (Ackerman et al. 2000).

Field studies in the Amazon basin have found that smoke from biomass burning can inhibit cloud formation (Koren et al. 2004; Andreae et al. 2004). To determine whether these local effects are significant at re- gional scales, we examined the eight regions defined by Duncan et al. (2003, their Fig. 3). They used the aerosol index data from the Total Ozone Mapping Spectrometer (TOMS) to produce a monthly regional aerosol index (MRAI) from 1979 to 1993 . We correlated the monthly anomalies of MRAI with monthly anomalies of cloud amounts. The results are shown in Table 5. There is significant interannual variability in biomass burning, so we might expect to see effects on seasonal cloud amounts. However, the correlations are very weak. With few exceptions, the correlation coefficients are smaller than 0.2 , meaning that less than $4 \%$ of the variance in cloud amount is explained by smoke. This does not necessarily mean that the effect of smoke on cloud amount is regionally insignificant; it may be that a correlation would show up if more stations were available to report clouds, or if the smoke index were available at higher spatial resolution.

Further support for the idea that aerosols have not been a strong factor contributing to the decreasing tropical cloud cover comes from Norris (2001). Although that study was carried out for ocean rather than for land clouds, it found that low-level cloud cover did not decrease over the northern Indian Ocean in spite of a likely increase of soot aerosol.

\section{Cloud effects on solar radiation at the surface ("global dimming")}

Solar irradiance measured by pyranometers ("global radiation," where global means that radiation from the entire sky-hemisphere, $2 \pi$ steradians, is received) has been analyzed for the past few decades from several 

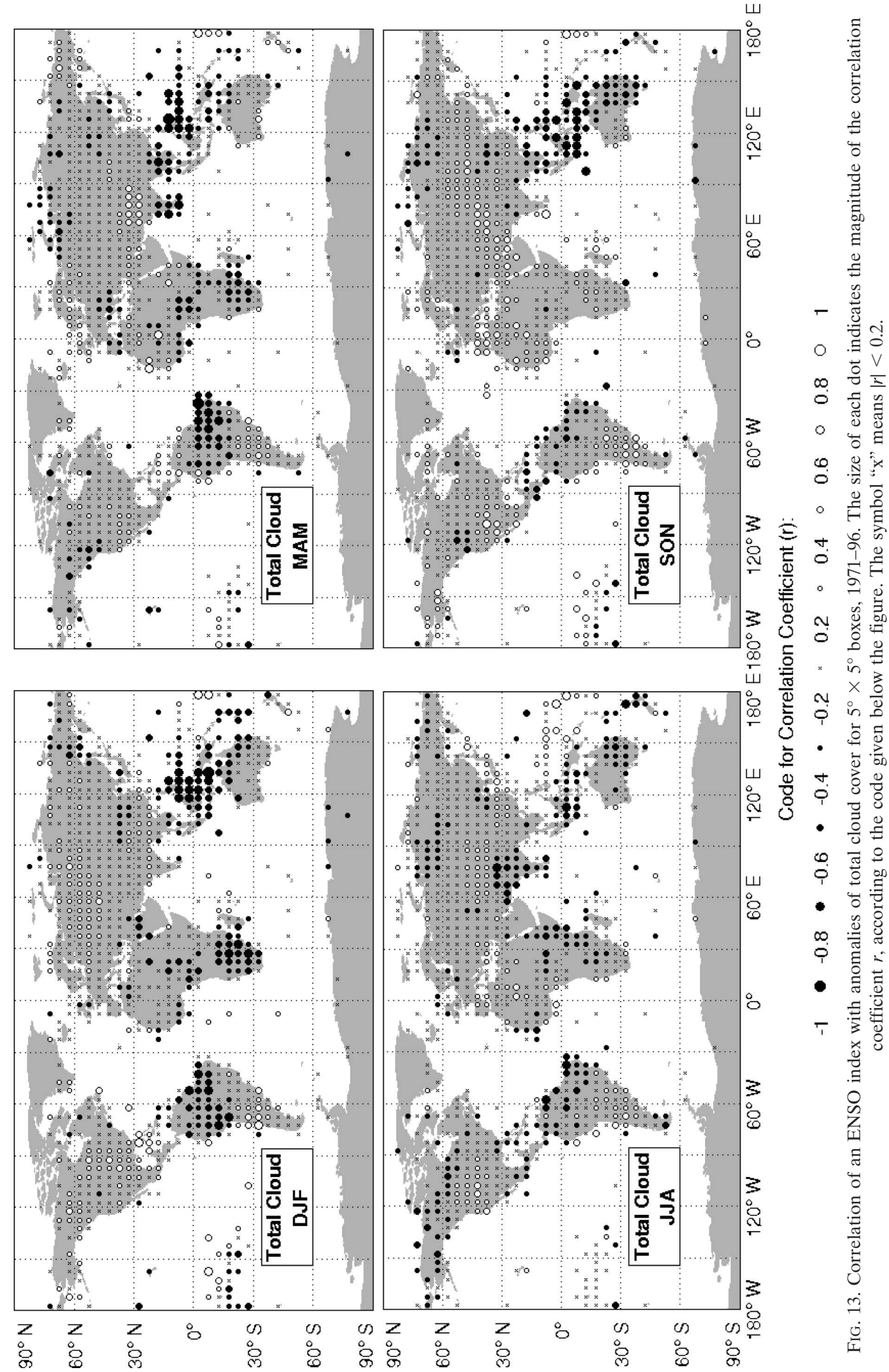





TABLE 5. Correlation of seasonal anomalies of cloud amount with an index of biomass burning. The regions are as defined in Fig. 3 of Duncan et al. (2003). The index of biomass burning is the MRAI, obtained from B. Duncan (2004, personal communication). Each entry of the table gives the average cloud amount followed by the correlation coefficient $(r)$; e.g., the top right entry has total cloud cover $=60 \%, r=-0.15$.

\begin{tabular}{|c|c|c|c|c|c|c|c|c|c|c|c|c|c|c|c|c|}
\hline \multirow{3}{*}{$\begin{array}{c}\text { Region } \\
\text { Burning season } \\
\text { Total cloud cover }\end{array}$} & \multirow{2}{*}{\multicolumn{2}{|c|}{$\begin{array}{c}\begin{array}{c}\text { Indonesia, } \\
\text { Malaysia, } \\
\text { New Guinea }\end{array} \\
\text { Jul-Oct }\end{array}$}} & \multirow{2}{*}{\multicolumn{2}{|c|}{$\begin{array}{c}\text { Brazil } \\
\text { Jul-Nov }\end{array}$}} & \multirow{2}{*}{\multicolumn{2}{|c|}{$\begin{array}{c}\text { Southern } \\
\text { Africa }\end{array}$}} & \multirow{2}{*}{\multicolumn{2}{|c|}{$\begin{array}{c}\begin{array}{c}\text { Northern } \\
\text { equatorial } \\
\text { Africa }\end{array} \\
\text { Oct-Mar }\end{array}$}} & \multirow{2}{*}{\multicolumn{2}{|c|}{$\begin{array}{c}\text { Central } \\
\text { America } \\
\text { and Mexico } \\
\text { Feb-May }\end{array}$}} & \multirow{2}{*}{\multicolumn{2}{|c|}{$\begin{array}{c}\begin{array}{c}\text { Canada } \\
\text { and Alaska }\end{array} \\
\text { May-Sep }\end{array}$}} & \multirow{2}{*}{\multicolumn{2}{|c|}{$\frac{\text { Siberia }}{\text { May-Sep }}$}} & \multirow{2}{*}{\multicolumn{2}{|c|}{$\begin{array}{c}\text { Southeast } \\
\text { Asia }\end{array}$}} \\
\hline & & & & & & & & & & & & & & & & \\
\hline & 73 & 0.12 & 54 & 0.02 & 38 & -0.10 & 60 & -0.31 & 47 & 0.05 & 68 & -0.13 & 65 & -0.00 & 60 & -0.15 \\
\hline Fog & 0 & & ( & & & & & & & & & & & & & 0.01 \\
\hline & 1 & -0.0 & 5 & -0.0 & 2 & & 2 & & & & $\varepsilon$ & & 4 & -0 & & -0 . \\
\hline & 11 & & 11 & -0.05 & 13 & -0 & 8 & -0 & 6 & -0 & 22 & & 12 & -0 & 22 & -0.05 \\
\hline Cumulus & 15 & 0.03 & 12 & -0.08 & 10 & -0.17 & 12 & -0.13 & 14 & -0 . & 9 & -0.09 & 8 & -0.06 & 7 & -0.03 \\
\hline Cumulonimbus & 8 & -0.11 & 2 & -0.09 & 1 & -0.12 & 8 & -0.31 & 2 & -0.12 & 2 & 0.03 & 13 & -0.02 & 6 & -0.06 \\
\hline Nimbostratus & 4 & -0.14 & 2 & -0.07 & 1 & -0.14 & 1 & -0.11 & 1 & -0.06 & 8 & -0.06 & 4 & -0.02 & 7 & -0.13 \\
\hline Altostratus & 7 & -0.01 & 5 & -0.05 & 1 & -0.08 & 1 & -0.13 & 4 & -0.03 & 1 & 0.01 & 3 & 0.01 & 2 & -0.05 \\
\hline Altocumulus & 31 & 0.00 & 16 & -0.10 & 11 & -0.16 & 20 & -0.29 & 12 & -0.00 & 25 & -0.08 & 17 & -0.04 & 19 & -0.12 \\
\hline High (cirriform) & 41 & 0.02 & 19 & -0.01 & 7 & -0.01 & 30 & -0.13 & 18 & -0.12 & 27 & -0.05 & 28 & 0.09 & 18 & -0.17 \\
\hline
\end{tabular}

stations, mostly in Eurasia. A "dimming" of the global radiation at many of these stations was seen from $\sim 1960$ to 1985 (Gilgen et al. 1998), which appears to have reversed sign in 1985, with a "brightening" observed during 1985-2000 (Wild et al. 2005). However, many of the trends are too noisy to show these two trends clearly. If clouds are responsible, we would expect to see an increasing trend from 1971 to 1985, then a decreasing trend from 1985 to 1996 . We have plotted (not shown) the time series of cloud cover for several of the stations that have the most reliable pyranometer records, and compared them to the pyranometer data supplied by M. Wild (2004, personal communication): Singapore, Beijing, Moscow, and three stations in Japan. We found no significant correlation with cloud cover changes. The global dimming and brightening phenomena may instead be caused by trends of the anthropogenic aerosol burden, as proposed by Liepert et al. (2004). The dimming is also apparently mostly restricted to urban areas (Alpert et al. 2005). Recently Norris and Wild (2007) have removed the effects of cloud variations from time series of monthly solar irradiance at European stations, obtaining a residual dimming and brightening pattern with much less noise; they attribute this residual to aerosol effects.

\section{Clouds and temperatures}

\section{a. Relation of cloud cover to surface temperature}

Clouds affect surface temperature, and surface temperature can also affect cloud development. In many regions there are strong correlations. Figure 15 shows what we typically find, using as an example the weather stations in a grid box in western Russia: cloud cover is positively correlated with temperature in January and negatively correlated in July. The direction of causality cannot be determined from these plots. It seems likely that in summer the correlation is due to the cooling effect of clouds. In winter the correlation could also be a direct warming effect of clouds via longwave radiation, especially in the continental interiors where surface-based temperature inversions are common (section 4 of Hudson and Brandt 2005). But the correlation could instead result from mutual control by synoptic
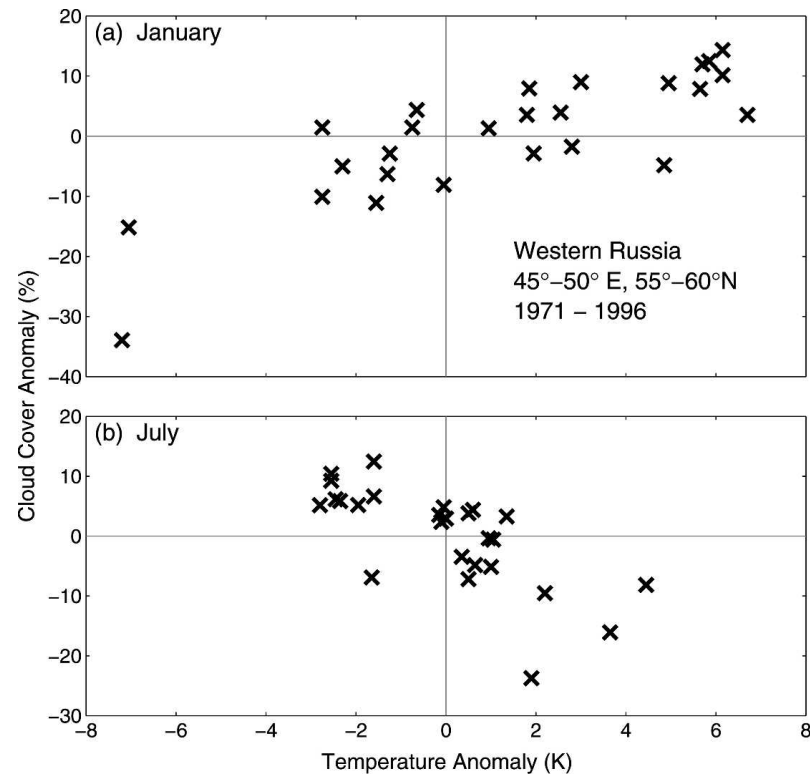

FIG. 15. Monthly anomalies of daytime total cloud cover vs monthly anomalies of diurnal average surface air temperature, for each year in $1971-96$, for one $5^{\circ} \times 5^{\circ}$ grid box in western Russia: (a) January and (b) July. 

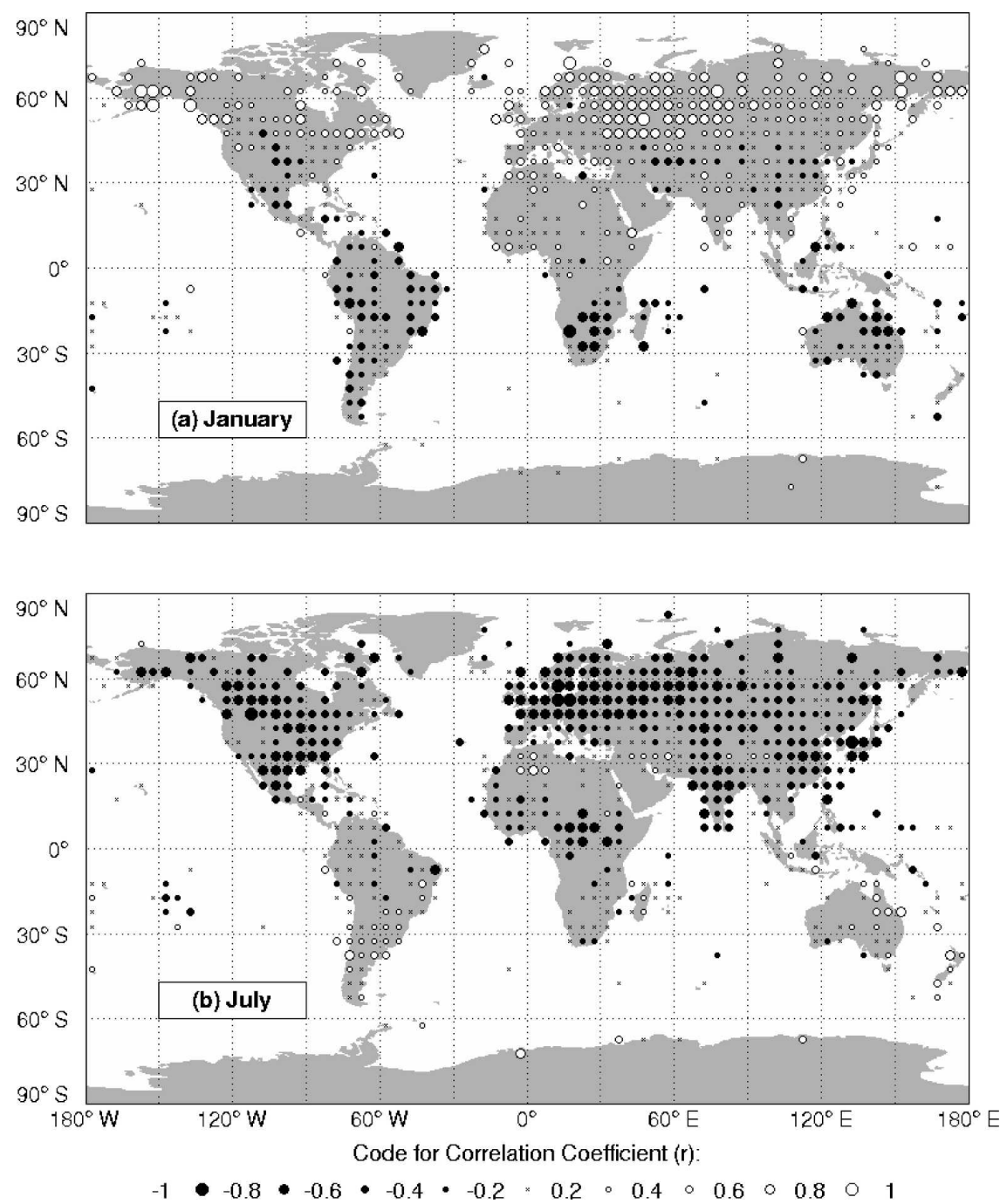

FIG. 16. Correlation of monthly anomalies of daytime total cloud cover (assumed to represent nighttime anomalies as well, according to Fig. 3a) with monthly anomalies of diurnal average surface air temperature, for $5^{\circ} \times 5^{\circ}$ boxes, 1971-96. The size of each dot indicates the magnitude of the correlation coefficient $r$, according to the code given below the figure.; $\mathrm{x}$ means $|r|<0.2$.

variability. A positive cloud anomaly and a positive temperature anomaly could both result from advection of marine air or passage of a warm front. Figure 16 shows that the seasonal correlation pattern is coherent across the middle latitudes of both the Northern and Southern Hemispheres. These two extreme months, January and July, are the months that exhibit the strongest correlations.

In plots such as Fig. 15 there is no clear identification of dependent and independent variables, and both variables are subject to measurement errors, so to obtain a linear relationship we minimize neither the vertical nor the horizontal distances to the fitted line. Instead we must estimate error ellipses for the points. The uncer- tainty in a seasonal mean cloud cover is obtained by plotting the error as a function of the number of observations made during the season, randomly selecting subsets of various size from the complete set of observations, to form means with inadequate sampling (Fig. 5 of Warren et al. 1986). We used the same procedure to estimate the error in seasonal mean surface air temperature as a function of the number of observations. That procedure gave us a different error ellipse for each point. (The typical error was $0.4-0.8 \mathrm{~K}$ in temperature; $2 \%$ in cloud cover.) A linear-regression procedure (Press et al. 2002, their section 15.3) was then applied to the data from each weather station, and the resulting slopes (change in cloud cover per change in tempera- 


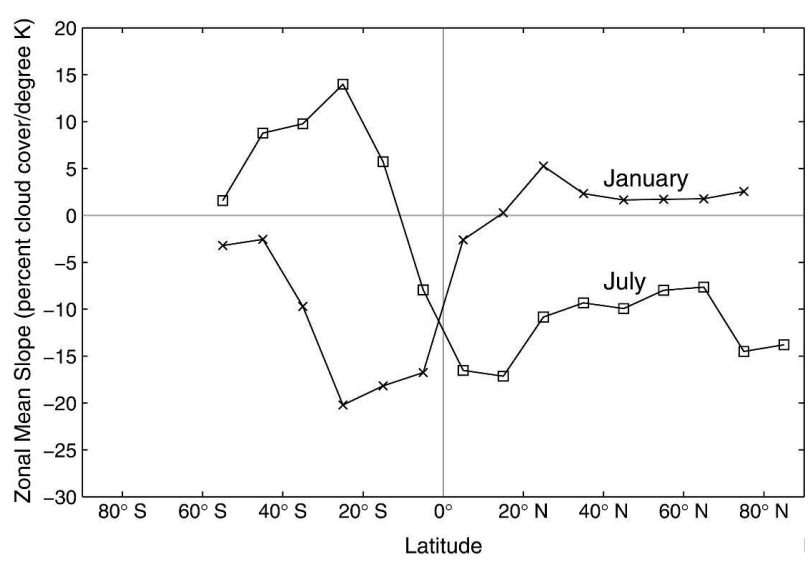

FIG. 17. Slope of the linear relation of total cloud cover to surface air temperature, zonally averaged, in percent cloud cover per kelvin.

ture) averaged to $10^{\circ}$ boxes. A slope was included in the average if the slope exceeded its uncertainty, or if the uncertainty was less than $1 \% \mathrm{~K}^{-1}$. Zonal averages of the slopes are shown in Fig. 17. The seasonal reversal is clear. In the Northern Hemisphere, the average slope is $-10 \%$ cloud cover per kelvin in July, and $+2 \%$ in January. These relations have been investigated in more detail for some regions by Sun et al. (2000), who determined the dependence of this slope on solar elevation, snow cover, and humidity.

\section{b. Relation of cloud-base height to surface temperature}

Our datasets include reported base heights for the low cloud types ( $\mathrm{St}, \mathrm{Sc}, \mathrm{Cu}$, and $\mathrm{Cb}$ ). From our analyses, the average base heights appear to be weakly dependent on seasonal surface temperature. There is considerable scatter in plots of height versus temperature for individual boxes, and even for individual zones, so in Fig. 18 we show only the averages for three broad latitudinal bands: $25^{\circ}-80^{\circ} \mathrm{N}, 25^{\circ} \mathrm{N}-25^{\circ} \mathrm{S}$, and $25^{\circ}-60^{\circ} \mathrm{S}$. (Values for midlatitudes are shown for summer and winter; only annual values are shown for the tropical zone.) As we did for the analysis of cloud cover versus temperature described in the previous section, here also we performed linear regression with errors in both axes. (We determined that the root-mean-square sampling error for mean base height is proportional to $n^{-1 / 2}$, where $n$ is the number of observations; the error is about $80 \mathrm{~m}$ for $n=30$.) In the midlatitudes, cloud-base height $\left(z_{b}\right)$ generally increases with increasing temperature for all four types, more in summer than in winter. In the Tropics there is no consistent pattern, with $\mathrm{Cb}$ and Sc showing negative correlations and St showing a positive correlation.
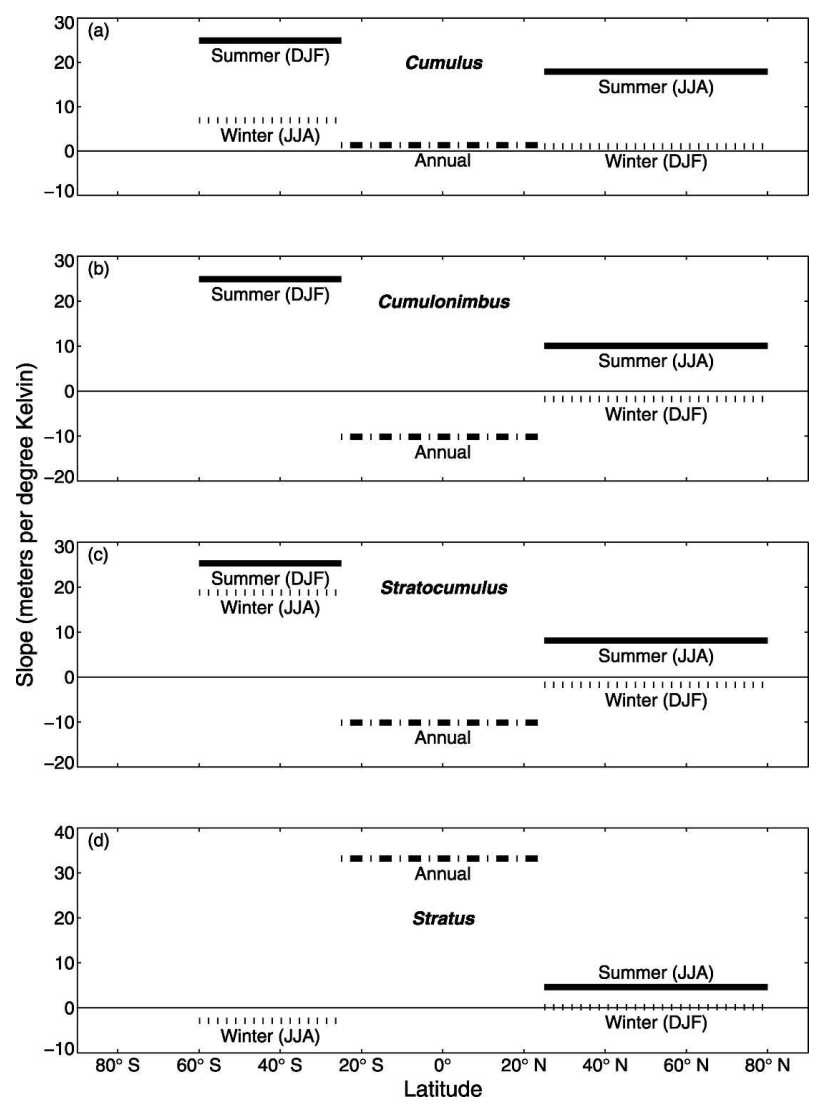

FIG. 18. Slope of the linear relation of cloud-base height to surface air temperature for the four low cloud types, averaged over three broad latitude bands: $25^{\circ}-80^{\circ} \mathrm{N}, 25^{\circ} \mathrm{N}-25^{\circ} \mathrm{S}$, and $25^{\circ}$ $60^{\circ} \mathrm{S}$.

An increase of $z_{b}$ with temperature is to be expected if surface relative humidity is held constant. For a standard surface relative humidity of $77 \%$ (Manabe and Wetherald 1967), the dewpoint depression increases from 4.3 to $4.5 \mathrm{~K}$ if the surface air temperature $\left(T_{s}\right)$ increases from $25^{\circ}$ to $30^{\circ} \mathrm{C}$, and the lifting condensation level increases by about $20 \mathrm{~m}$, or $4 \mathrm{~m} \mathrm{~K}^{-1}$. However, the observed slopes $d z_{b} / d T_{s}$ shown in Fig. 18 are often larger than $4 \mathrm{~m} \mathrm{~K}^{-1}$, particularly in summer, so other influences must also be acting. One possibility is that in summer, higher cloud bases are an indication of a drier atmosphere and less fractional cloud cover, resulting in more solar radiation at the surface and higher surface temperatures. The fact that slopes are larger for cumuliform clouds than for stratiform clouds suggests that this is a likely explanation. It could be tested by correlating $z_{b}$ with amount-when-present.

Cloud-base heights were diagnosed from radiosonde reports at 795 stations by Chernykh et al. (2001); they concluded that the global average cloud-base height decreased by $44 \mathrm{~m} \mathrm{decade}^{-1}$ for the period 1964-98. The 
visual reports we analyze here indicate smaller trends, and they are not always negative; the global annual average trends for $\mathrm{St}, \mathrm{Sc}, \mathrm{Cu}$, and $\mathrm{Cb}$ are $+10,-8,0$, and $-18 \mathrm{~m}$ decade $^{-1}$, respectively. Seidel and Durre (2003) pointed out that the trends of Chernykh et al. were likely an artifact of the increasing vertical resolution of radiosonde reports over that 35-yr period.

\section{c. Diurnal temperature range}

Reductions of the diurnal temperature range (DTR) over the past few decades have been documented in some continental regions, and either an increase of cloud cover, an increase of aerosols, or both, have been suggested as contributors (Karl et al. 1995; Dai et al. 1997, 1999). Using the new cloud databases, a more comprehensive study relating the variations of DTR to variations of cloud cover on various time scales would now be possible, allowing for investigation of the contributions of the different cloud types, worldwide.

\section{Conclusions}

Visual observations of cloud cover and cloud types at weather stations appear to be useful for climatological studies of the diurnal, seasonal, and interannual variations of clouds, provided that the reports are subjected to quality control and that adequate numbers of observations are available. Significant regional trends are found for many cloud types, and these trends are coherent across national boundaries, so they invite explanation as real climatic changes. We have found the expected correlations between cloud variations over Europe with the Northern Annular Mode, and also in many regions between cloud variations and ENSO. We have also found plausible relations of clouds with surface temperature in the middle latitudes, changing sign as expected from summer to winter. In the global average, convective clouds appear to have increased slightly at the expense of stratiform clouds.

Although there are large regional changes in cloudtype amounts, and significant changes in the global averages of some cloud types, the changes compensate each other to result in only a small trend of global average land cloud cover, $-0.7 \%$ decade $^{-1}$. This small negative trend is further compensated by a small positive trend over the ocean of $+0.4 \%$ decade $^{-1}$ (Norris 1999), resulting in almost no trend for global average cloud cover over the past few decades. The important caveat, however, is that these analyses terminate in 1996. It will be important to prepare cloud datasets for the more recent years, when changes may become more noticeable with increased global warming.
The different cloud types result from different meteorological processes and have different effects on radiation fluxes. We therefore emphasize the importance of examining variations in individual cloud types, rather than just total cloud cover. The land-station climatology we have introduced here is available to the scientific community (Hahn and Warren 2003; http:// www.atmos.washington.edu/CloudMap/); it should be useful for further investigation and attribution of the interannual variations of the various cloud types.

Acknowledgments. We have benefited from discussions with J. Michael Wallace, Chris Bretherton, Kevin Trenberth, Aiguo Dai, Jay Fein, Joel Norris, and Chris Folland. Bryan Duncan provided his aerosol index data for the study of smoke effects on clouds, and Martin Wild provided the pyranometer analyses. Ignatius Rigor produced our Web site of cloud maps. Helpful comments on the manuscript were received from three anonymous reviewers. The research was supported by NSF's Climate Dynamics Program and NOAA's Climate Change Data and Detection (CCDD) program, under NSF Grants ATM-02-42124 and ATM-02-42128.

\section{REFERENCES}

Ackerman, A. S., O. B. Toon, D. E. Stevens, A. J. Heymsfield, V. Ramanathan, and E. J. Welton, 2000: Reduction of tropical cloudiness by soot. Science, 288, 1042-1047.

Alpert, P., P. Kishcha, Y. J. Kaufman, and R. Schwarzbard, 2005: Global dimming or local dimming?: Effect of urbanization on sunlight availability. Geophys. Res. Lett., 32, L17802, doi:10.1029/2005GL023320.

Andreae, M. O., D. Rosenfeld, P. Artaxo, A. A. Costa, G. P. Frank, K. M. Longo, and M. A. F. Silva-Dias, 2004: Smoking rain clouds over the Amazon. Science, 303, 1337-1342.

Beesley, J. A., and R. E. Moritz, 1999: Toward an explanation of the annual cycle of cloudiness over the Arctic Ocean. J. Climate, 12, 395-415.

Boucher, O., 1999: Air traffic may increase cirrus cloudiness. $\mathrm{Na}$ ture, 397, 30-31.

Campbell, G. G., 2004: View angle dependence of cloudiness and the trend in ISCCP cloudiness. Preprints, 13th Conf. on Satellite Meteorology and Oceanography, Norfolk, VA, Amer. Meteor. Soc., CD-ROM, P6.7.

Cess, R. D., and Coauthors, 1990: Intercomparison and interpretation of climate feedback processes in 19 atmospheric general circulation models. J. Geophys. Res., 95, 16 601-16 615.

Charlson, R. J., S. E. Schwartz, J. M. Hales, R. D. Cess, J. A. Coakley Jr., J. E. Hansen, and D. J. Hofmann, 1992: Climate forcing by anthropogenic aerosols. Science, 255, 423-430.

Chernykh, I. V., O. A. Alduchov, and R. E. Eskridge, 2001: Trends in low and high cloud boundaries and errors in height determination of cloud boundaries. Bull. Amer. Meteor. Soc., 82, 1941-1947.

Dai, A., A. D. Del Genio, and I. Y. Fung, 1997: Clouds, precipitation, and temperature range. Nature, 386, 665-666.

_ K. E. Trenberth, and T. R. Karl, 1999: Effects of clouds, soil 
moisture, precipitation, and water vapor on diurnal temperature range. J. Climate, 12, 2451-2473.

— , T. R. Karl, B. Sun, and K. E. Trenberth, 2006: Recent trends in cloudiness over the United States: A tale of monitoring inadequacies. Bull. Amer. Meteor. Soc., 87, 597-606.

Deser, C., A. S. Phillips, and J. W. Hurrell, 2004: Pacific interdecadal climate variability: Linkages between the Tropics and the North Pacific during boreal winter since 1900. J. Climate, 17, 3109-3124.

Duncan, B. N., R. V. Martin, A. C. Staudt, R. Yevich, and J. A. Logan, 2003: Interannual and seasonal variability of biomass burning emissions constrained by satellite observations. $J$. Geophys. Res., 108, 4100, doi:10.1029/2002JD002378.

Gilgen, H., M. Wild, and A. Ohmura, 1998: Means and trends of shortwave irradiance at the surface estimated from global energy balance archive data. J. Climate, 11, 2042-2061.

Groisman, P. Ya., R. W. Knight, T. R. Karl, D. R. Easterling, B. Sun, and J. H. Lawrimore, 2004: Contemporary changes of the hydrological cycle over the contiguous United States: Trends derived from in situ observations. J. Hydrometeor., 5, 64-85.

Hahn, C. J., and S. G. Warren, 1999: Extended edited cloud reports from ships and land stations over the globe, 1952-1996. Tech. Rep. NDP-026C, Carbon Dioxide Information Analysis Center, 79 pp.

— wide, 1971-1996. Tech. Rep. NDP-026D, Carbon Dioxide Information Analysis Center, 35 pp. [Available online at http:// cdiac.ornl.gov/ftp/ndp026d/.]

$\longrightarrow,-$, and J. London, 1995: The effect of moonlight on observation of cloud cover at night, and application to cloud climatology. J. Climate, 8, 1429-1446.

Harrison, E. F., P. Minnis, B. R. Barkstrom, V. Ramanathan, R. D. Cess, and G. G. Gibson, 1990: Seasonal variation of cloud radiative forcing derived from the Earth Radiation Budget Experiment. J. Geophys. Res., 95, 18 687-18 703.

Henderson-Sellers, A., 1986: Cloud changes in a warmer Europe. Climatic Change, 8, 25-52.

_ 1989: North American total cloud amount variations this century. Palaeogeogr. Palaeoclimatol. Palaeoecol., 75, 175-194.

Houghton, J. T., Y. Ding, D. J. Griggs, M. Noguer, P. J. van der Linden, X. Dai, K. Maskell, and C. A. Johnson, Eds., 2001: Climate Change 2001: The Scientific Basis. Cambridge University Press, $881 \mathrm{pp}$.

Houze, R. A., Jr., 1993: Cloud Dynamics. Academic Press, 573 pp.

Hudson, S. R., and R. E. Brandt, 2005: A look at the surfacebased temperature inversion on the Antarctic Plateau. J. Climate, 18, 1673-1696.

Hurrell, J. W., 1995: Decadal trends in the North Atlantic Oscillation: Regional temperatures and precipitation. Science, 269, 676-679.

Jones, P. A., and A. Henderson-Sellers, 1992: Historical records of cloudiness and sunshine in Australia. J. Climate, 5, 260-267.

Kaiser, D. P., 1998: Analysis of total cloud amount over China, 1951-1994. Geophys. Res. Lett., 25, 3599-3602.

, 2000: Decreasing cloudiness over China: An updated analysis examining additional variables. Geophys. Res. Lett., 27, 2193-2196.

—_, and Y. Qian, 2002: Decreasing trends in sunshine duration over China for 1954-1998: Indication of increased haze pollution? Geophys. Res. Lett., 29, 2042, doi:10.1029/ 2002 GL016057.

Karl, T. R., and P. M. Steurer, 1990: Increased cloudiness in the
United States during the first half of the twentieth century: Fact or fiction? Geophys. Res. Lett., 17, 1925-1928.

- R. W. Knight, G. Kukla, and J. Gavin, 1995: Evidence for radiative effects of anthropogenic sulfate aerosols in the observed climate record. Aerosol Forcing of Climate, R. Charlson and J. Heintzenberg, Eds., Wiley, 363-382.

Koren, I., Y. J. Kaufman, L. A. Remer, and J. V. Martins, 2004: Measurement of the effect of Amazon smoke on inhibition of cloud formation. Science, 303, 1342-1345.

Krüger, O., and H. Grassl, 2004: Albedo reduction by absorbing aerosols over China. Geophys. Res. Lett., 31, L02108, doi:10.1029/2003GL019111.

Lanzante, J. R., 1996: Resistant, robust and non-parametric techniques for the analysis of climate data: Theory and examples, including applications to historical radiosonde station data. Int. J. Climatol., 16, 1197-1226.

Liepert, B. G., J. Feichter, U. Lohmann, and E. Roeckner, 2004: Can aerosols spin down the water cycle in a warmer and moister world? Geophys. Res. Lett., 31, L06207, doi:10.1029/ 2003 GL019060.

Manabe, S., and R. T. Wetherald, 1967: Thermal equilibrium of the atmosphere with a given distribution of relative humidity. J. Atmos. Sci., 24, 241-259.

Maugeri, M., Z. Bagnati, M. Brunetti, and T. Nanni, 2001: Trends in Italian total cloud amount, 1951-1996. Geophys. Res. Lett., 28, 4551-4554

Meyers, S. D., J. J. O'Brien, and E. Thelin, 1999: Reconstruction of monthly SST in the tropical Pacific Ocean during 18681993 using adaptive climate basis functions. Mon. Wea. Rev., 127, 1599-1612.

Milewska, E. J., 2004: Baseline cloudiness trends in Canada 1953 2002. Atmos.-Ocean, 42, 267-280.

Minnis, P., J. K. Ayers, R. Palikonda, and D. Phan, 2004: Contrails, cirrus trends, and climate. J. Climate, 17, 1671-1685.

NCDC, 1962: History of the international code. TDF-13 Reference Manual, National Climatic Data Center, 0.6-0.10.

Norris, J. R., 1998: Low cloud structure over the ocean from surface observations. Part II: Geographical and seasonal variations. J. Climate, 11, 383-403.

- 1999: On trends and possible artifacts in global ocean cloud cover between 1952 and 1995. J. Climate, 12, 1864-1870.

—, 2001: Has northern Indian Ocean cloud cover changed due to increasing anthropogenic aerosol? Geophys. Res. Lett., 28, 3271-3274.

_ 2005a: Multidecadal changes in near-global cloud cover and estimated cloud cover radiative forcing. J. Geophys. Res., 110, D08206, doi:10.1029/2004JD005600.

- 2005b: Trends in upper-level cloud cover and surface divergence over the tropical Indo-Pacific Ocean between 1952 and 1997. J. Geophys. Res., 110, D21110, doi:10.1029/2005JD006183.

— , and M. Wild, 2007: Trends in direct and indirect aerosol radiative effects over Europe inferred from observed cloud cover, solar "dimming," and solar "brightening." J. Geophys. Res., in press.

Park, S., and C. B. Leovy, 2000: Winter North Atlantic low cloud anomalies associated with the Northern Hemisphere annular mode. Geophys. Res. Lett., 27, 3357-3360.

Pinto, J. O., 1998: Autumnal mixed-phase cloudy boundary layers in the Arctic. J. Atmos. Sci., 55, 2016-2038.

Press, W. H., S. A. Teukolsky, W. T. Vetterling, and B. P. Flannery, 2002: Numerical Recipes in C: The Art of Scientific Computing. 2d ed. Cambridge University Press, 994 pp. 
Qian, W., L. Quan, and S. Shi, 2002: Variations of the dust storm in China and its climatic control. J. Climate, 15, 1216-1229.

-, X. Tang, and L. Quan, 2004: Regional characteristics of dust storms in China. Atmos. Environ., 38, 4895-4907.

Qian, Y., D. P. Kaiser, L. R. Leung, and M. Xu, 2006: More frequent cloud-free sky and less surface solar radiation in China from 1955 to 2000. Geophys. Res. Lett., 33, L01812, doi:10.1029/2005GL024586.

Ramanathan, V., R. D. Cess, E. F. Harrison, P. Minnis, B. R. Barkstrom, E. Ahmad, and D. Hartmann, 1989: Cloudradiative forcing and climate: Results from the Earth Radiation Budget Experiment. Science, 243, 57-63.

— on South Asian climate and hydrological cycle. Proc. Natl. Acad. Sci. USA, 102, 5326-5333.

Rossow, W. B., and E. N. Dueñas, 2004: The International Satellite Cloud Climatology Project (ISCCP) Web site: An online resource for research. Bull. Amer. Meteor. Soc., 85, 167-172.

Seidel, D. J., and I. Durre, 2003: Comments on "Trends in low and high cloud boundaries and errors in height determination of cloud boundaries." Bull. Amer. Meteor. Soc., 84, 237-240.

Shine, K. P., 2005: Comments on "Contrails, cirrus trends, and climate." J. Climate, 18, 2781-2782.

Stubenrauch, C. J., and U. Schumann, 2005: Impact of air traffic on cirrus coverage. Geophys. Res. Lett., 32, L14813, doi:10.1029/2005GL022707.

Sun, B., 2003: Cloudiness over the contiguous United States: Contemporary changes observed using ground-based and ISCCP D2 data. Geophys. Res. Lett., 30, 1053, doi:10.1029/ 2002 GL015887.

— former Soviet Union. Int. J. Climatol., 20, 1097-1111.

— cloud formation: A reassessment. J. Geophys. Res., 107, 4211, doi:10.1029/2001JD000560.

- and P. Ya. Groisman, 2004: Variations in low cloud cover over the United States during the second half of the twentieth century. J. Climate, 17, 1883-1888.

- — - R. S. Bradley, and F. T. Keimig, 2000: Temporal changes in the observed relationship between cloud cover and surface air temperature. J. Climate, 13, 4341-4357.

, and I. I. Mokhov, 2001: Recent changes in cloud-type frequency and inferred increases in convection over the United States and the former USSR. J. Climate, 14, 1864-1880.
Thompson, D. W. J., and J. M. Wallace, 2000: Annular modes in the extratropical circulation. Part I: Month-to-month variability. J. Climate, 13, 1000-1016.

Trenberth, K. E., and D. P. Stepaniak, 2001: Indices of El Niño evolution. J. Climate, 14, 1697-1701.

- , and D. J. Shea, 2005: Relationships between precipitation and surface temperature. Geophys. Res. Lett., 32, L14703, doi:10.1029/2005GL022760.

— J. M. Caron, D. P. Stepaniak, and S. Worley, 2002: Evolution of El Niño-Southern Oscillation and global atmospheric surface temperatures. J. Geophys. Res., 107, 4065, doi:10.1029/2000JD000298.

Trigo, R. M., T. J. Osborn, and J. M. Corte-Real, 2002: The North Atlantic Oscillation influence on Europe: Climate impacts and associated physical mechanisms. Climate Res., 20, 9-17.

Wang, X., and J. R. Key, 2003: Recent trends in Arctic surface, cloud, and radiation properties from space. Science, 200, $1725-1728$

- Z. Dong, J. Zhang, and L. Liu, 2004: Modern dust storms in China: An overview. J. Arid Environ., 58, 559-574.

Warren, S. G., and C. J. Hahn, 2002: Cloud climatology. Encyclopedia of Atmospheric Sciences, J. R. Holton, J. Pyle, and J. A. Curry, Eds., Oxford University Press, 476-483.

- — - J. London, R. M. Chervin, and R. L. Jenne, 1986: Global distribution of total cloud cover and cloud type amounts over land. NCAR Tech. Note TN-273+STR, 229 pp. , and - 1988: Global distribution of total cloud cover and cloud type amounts over the ocean. NCAR Tech. Note TN-317+STR, 212 pp.

$\longrightarrow$, - $\longrightarrow$, and 1991: Cloud hole over the United States? Bull. Amer. Meteor. Soc., 72, 237-238.

Wild, M., and Coauthors, 2005: From dimming to brightening: Decadal changes in solar radiation at Earth's surface. Science, 308, 847-850.

WMO, 1956: International Cloud Atlas. World Meteorological Organization, $62 \mathrm{pp}$. plus 72 plates.

_ 1974: Manual on Codes. Vol. 1. World Meteorological Organization Publication 306, 348 pp.

Wylie, D., D. L. Jackson, W. P. Menzel, and J. J. Bates, 2005: Trends in global cloud cover in two decades of HIRS observations. J. Climate, 18, 3021-3031.

Zhao, C., X. Dabu, and Y. Li, 2004: Relationship between climatic factors and dust storm frequency in Inner Mongolia of China. Geophys. Res. Lett., 31, L01103, doi:10.1029/2003GL018351. 